\title{
ROCK MAGNETISM AND THE INTERPRETATION OF ANISOTROPY OF MAGNETIC SUSCEPTIBILITY
}

\author{
P. Rochette, ${ }^{1} \mathrm{M}$. Jackson, ${ }^{2}$ and C. Aubourg \\ Laboratoire de Géophysique Interne et Tectonophysique \\ Observatoire de Grenoble, Grenoble, France
}

\begin{abstract}
The conventional rules, derived from empirical and theoretical considerations, for the interpretation of anisotropy of magnetic susceptibility (AMS) in terms of microstructure and deformation are subject to numerous exceptions as a result of particular rock magnetic effects. Unusual relationships between structural and magnetic axes (so-called inverse or intermediate magnetic fabrics) can occur because of the presence of certain magnetic minerals, either single domain magnetite or various paramagnetic minerals. When more than one mineral is responsible for magnetic susceptibility, various problems appear, in particular the impossibility of using an-
\end{abstract}

isotropy to make quantitative inferences on the intensity of the preferred orientation and consequently on strain. In ferromagnetic grains, AMS may also be influenced by the magnetic memory of the grains (including natural remanence). The effect of alternating field or thermal demagnetization on AMS is briefly discussed. Various rock magnetic techniques, specific to AMS interpretation, have to be developed for a better assessment of the geological significance of AMS data. These techniques mainly rely on measurements of susceptibility versus magnetic field and temperature, together with anisotropy of remanence.

\section{INTRODUCTION}

Magnetic susceptibility $K$ is defined by $\mathbf{M}=[K] \times \mathbf{H}$, where $\mathbf{M}$ is the induced magnetization of the material and $\mathbf{H}$ is the inducing magnetic field. As both $\mathbf{M}$ and $\mathbf{H}$ are expressed in amperes per meter, volumetric susceptibility $K$ is dimensionless (written as "SI"), while mass susceptibility $\chi$ $=K / \rho$ is in cubic meters per kilogram. Susceptibility varies in the general case according to field and temperature values and may vary according to the measurement direction resulting in a nonparallelism between $\mathbf{H}$ and $\mathbf{M}$ vectors. $K$ is most often measured at room temperature and low-field strength $(\leqslant 1 \mathrm{mT})$ because in such conditions, (1) experimental procedures are the easiest, allowing high sensitivity and rapid measurements, even in the field; (2) $K$ is a good estimate of the in situ induced magnetization of a rock in the Earth's field, therefore serving as a basis for magnetic anomaly interpretations; and (3) $K$ can be correctly approximated by a second-order symmetric tensor, a situation which greatly facilitates the measurement of susceptibility anisotropy. At the grain scale the anisotropy of magnetic susceptibility, as many other physical properties such as optical refractive index, mechanical constant, conductivity, etc., is controlled by the type and directions of the crystallographic system. However, other phenomena overcome the crystallographic control in minerals with very high susceptibility such as magnetite. In such a case the anisotropy of a multidomain grain is simply the image of the shape of the

\footnotetext{
'Permanently at Faculté St-Jérôme, Marseille, France.

2Permanently at Institute for Rock Magnetism, University of Minnesota, Minneapolis.
}

grain (maximum susceptibility parallel to the long axis and minimum susceptibility parallel to the short axis).

The anisotropy of magnetic susceptibility (AMS) is a physical property of rocks which is used for petrofabric and structural studies (see Owens and Bamford [1976], Hrouda [1982], Borradaile [1988], Lowrie [1989], and Jackson and Tauxe [1991], for recent reviews). Its principle is simple: AMS arises from the preferred orientation of anisotropic magnetic minerals, in other words, the magnetic fabric. The preferred orientation of crystallographic axes, themselves often controlling grain shape, determines the AMS for the vast majority of minerals. The shape preferred orientation of individual grains or of grain clusters, the second case corresponding to the "distribution anisotropy" introduced by Hargraves et al. [1991], plays a direct role in AMS essentially in the case of magnetite.

The AMS technique is gaining numerous users for a wide range of applications in Earth sciences because of (1) applicability to practically every rock and soft sediment type; (2) high sensitivity, which allows one to determine fabrics in rocks previously seen as isotropic (for example, rocks with a fabric due to flow of magma, bottom water currents, weak deformation), therefore opening new research fields; (3) timely operation (about 15 min per specimen including field sampling and orientation, preparation, measurement, and processing) allowing statistical and cartographic fabric investigations, particularly useful to map complex structures such as those found in magmatic bodies or in tectonic units; (4) possibilities for semiquantitative and quantitative application in terms of fabric and deformation intensity and symmetry; and (5) use as a new tool to constrain 
paleomagnetic interpretations in terms of age of the natural remanent magnetization (NRM), better definition of structural corrections, possible deviation of NRM from the geomagnetic field, etc.

The output of AMS measurements is an ellipsoid of magnetic susceptibility defined by the length and orientation of its three principal axes, $K_{1} \geqslant K_{2} \geqslant K_{3}$, i.e., the three eigenvectors of the susceptibility tensor. The parameters usually presented are the mean susceptibility $K_{m}=\left(K_{1}+K_{2}+K_{3}\right) /$ 3 and the anisotropy ratios $L=K_{1} / K_{2}, F=K_{2} / K_{3}$, and $P$ $=K_{1} / K_{3}$ (lineation, foliation, and degree of anisotropy, respectively). The choice of these parameters and a standardized way of presenting AMS data, used throughout this paper, are discussed by Ellwood et al. [1988]. The sensitivity of the individual measurements depends on the instrument used (either a low-field torquemeter, a spinner magnetometer (both measuring directly a susceptibility difference) a susceptibility bridge, or an inductive magnetometer), the value of $K_{m}$, and the anisotropy ratio $L$ for the sensitivity on $K_{1}$ direction and $F$ for $K_{3}$ (see discussion by Ellwood, [1984a] and Schmidt et al., [1988]). In the authors' opinion the most reliable, sensitive, and practical instruments presently available appear to be the torquemeter and the susceptibility bridge KLY-2 (manufactured by Geofyzika Brno). They allow one to determine reliable AMS directions in practically every rock type down to an anisotropy ratio of 1.002 .

Statistical treatment of AMS data from a set of specimens to define a site mean AMS tensor requires specific techniques, either analytical (the tensorial mean method of $J e$ linek [1978]) or numerical (the bootstrap method of Constable and Tauxe [1990]). These techniques must be preferred because they weigh each sample by its anisotropy ratios, provide mean anisotropy ratios more significant than the arithmetic mean of specimen values, and provide ellipses of confidence on the mean directions. Recently, Lienert [1991] has demonstrated by Monte-Carlo simulations that the ellipses given by Jelinek's [1978] simpler method are very good estimates of the dispersion. However, when differently oriented fabrics are superposed in a large set of samples, their orientation can be better separated by using processing methods for structural directions (e.g., density contours on a stereonet).

This paper reviews the applicability of the following general assumptions, often put forward when interpreting AMS data:

1. The AMS ellipsoid is coaxial to the petrofabric; the $K_{3}$ axis is perpendicular to the foliation, which may be the bedding plane in sedimentary rocks, the magmatic foliation plane in magmatic rock, or the flattening plane for solidstate deformed rocks; $K_{1}$ is parallel to the petrofabric lineation, which may be a tectonic lineation, a magmatic flow direction or a paleocurrent direction for sediments. Therefore the $K_{3}$ axis is named the pole of magnetic foliation, and $K_{1}$ gives the magnetic lineation direction.

2. The shape of the AMS ellipsoid is directly related to rock fabric. In a given rock type there is a simple quantitative relationship between $L$ or $F$ (or other parameters linked to the relative length of the susceptibility axes) and the intensities of linear or planar preferred orientations, respectively. In the case of solid-state deformation this implies a direct relationship between AMS and strain. Therefore a quantitative application of AMS is possible once a calibration with strain has been performed [e.g., Borradaile, 1991]. In many cases, only a semiquantitative interpretation is possible; i.e., a more anisotropic rock is more strained.

3. The AMS measurement is not affected by natural or artificial remanent magnetizations.

These assumptions can be compared to the basic requirements to obtain a paleomagnetic pole: The natural remanent magnetization (NRM) of a rock is parallel to the field in which it is acquired; the age of NRM is the formation age of the rock; the ancient field is represented by a geocentric axial dipole. In fact, as in paleomagnetism, the basic assumptions of AMS interpretation are not always fulfilled, and one needs various techniques to assess their validity in each case study.

Comparisons with case studies or models are not sufficient by themselves to establish truly scientific AMS interpretations. Models are usually too simple to account for the complexity of natural rocks, and empirically based deductions strongly limit the field of AMS applications. One can only conclude in terms of likelihood when dealing with AMS data that are not supported by structural measurements. When such structural measurements exist, the need for AMS study is minor because it brings few new information. Finally, a strong bias in the generality of an empirical law may arise from the natural tendency of workers in the field to only publish results that fit in the usual interpretation grid.

Among the independent pieces of evidence used to establish the validity of paleomagnetic results, rock magnetic criteria play a major role, in particular through the identification of magnetic minerals responsible for the NRM (i.e., magnetic mineralogy). As in paleomagnetism, where it has become standard practice to produce supplementary rock magnetic evidence, AMS interpretation should also be based on rock magnetic criteria.

One of the main breakthroughs in that direction in the last decade has been the wide recognition of a specific magnetic mineralogy related to AMS. In particular, there are important mineral sources of susceptibility that are not carriers of NRM (ferromagnetic minerals sensu lato): the diamagnetic, paramagnetic, and antiferromagnetic minerals, referred to as matrix minerals because they constitute the main volume fraction of common rocks [Owens and Bamford, 1976; Borradaile et al., 1985; Borradaile, 1987; Rochette, 1987]. The tools of magnetic mineralogy developed for paleomagnetism, mainly based on properties of artificial remanence [e.g., Lowrie and Heller, 1982], therefore have to be complemented by other techniques based on induced magnetization measurements as a function of field and temperature [Rochette et al., 1983; Rochette and Fillion, 1988].

Linear high-field susceptibility $\left(K_{H F}\right)$ measures the contribution of matrix minerals due to the saturation of ferromagnetic moment in high field. Therefore comparison of $K_{H F}$ 
with low-field susceptibility is among the best ways to assess the mineralogical origin of AMS. Properties of the matrix susceptibility, which is essentially of paramagnetic origin, have been reviewed already [Rochette, 1987; Jover et al., 1989]. Variation of susceptibility with temperature allows the identification of most paramagnetic minerals, whose susceptibility varies according to the Curie-Weiss law $\mathrm{K}=\mathrm{Cl}$ $(T-\theta) . C$ is a constant proportional to the amount of paramagnetic ions, and $\theta$ is the paramagnetic Curie constant, linked to the concentration of ions in the mineral and to the type of magnetic interaction. Therefore the study of low-field susceptibility versus temperature also allows one to estimate the paramagnetic contribution [e.g., Schultz-Krutisch and Heller, 1985]. Indirect estimates can also be derived from mineralogical and geochemical data. For paramagnetic susceptibility due to silicates or carbonates where $|\theta|<20 \mathrm{~K}$ a very good agreement is found between high-field measurement and the formula

$$
\begin{aligned}
K_{H F}= & -14.6+ \\
& d\left(25.2 t_{\mathrm{Fe}^{2+}}+33.4 t_{\mathrm{Fe}^{3+}}+33.8 t_{\mathrm{Mn}^{2+}}\right) 10^{-6} \mathrm{SI}
\end{aligned}
$$

where the diamagnetic susceptibility of quartz is taken as the one of all minerals, $d$ is the density of the rock, and the iron and manganese amounts are in atomic weight percent. Only $\mathrm{Fe}$ and $\mathrm{Mn}$ ions are taken into account because the other paramagnetic ions (from $\mathrm{Cr}, \mathrm{Ni}, \mathrm{Co}, \mathrm{Cu}, \mathrm{U}$, etc.) are practically always negligible compared to $\mathrm{Fe}$.

Another important recent development has been the use of the following various types of magnetic anisotropy, besides low-field susceptibility at room temperature, to help in AMS interpretation: (1) anisotropy of induced magnetization under high fields [Rochette and Fillion, 1988], which implement the former technique of high-field torquemeter [e.g., Coward and Whalley, 1979; Parma, 1988; Hrouda and Jelinek, 1990]; (2) anisotropy of low-field susceptibility at low temperature [e.g., Ihmlé et al., 1989]; and (3) anisotropy of various artificial remanences [Stephenson et al., 1986; Jackson, 1991]. The use of anhysteretic remanence (ARM) is quite practical [McCabe et al., 1985] but more or less limited to magnetite-bearing rocks, while anisotropy measurements with isothermal remanence (useful for goethite or hematite) [e.g., Tauxe et al., 1990] or thermoremanence [Cogné, 1987] are more difficult experimentally.

The main purpose of this paper is to discuss the validity of the three assumptions stated above in the light of rock magnetic evidence, to present examples where these assumptions fail, and to propose some rock magnetic tests for such exceptions. The first and most basic assumption, concerning the directional interpretation of AMS, will be discussed starting from a case study of 67 basaltic dikes from the ophiolite of Oman [Rochette et al., 1991]. The AMS due to the preferred orientation of early crystallized elongated titanomagnetite grains in the magmatic flow of dikes is expected to show $K_{3}$ axes perpendicular to the dike plane and $K_{1}$ axes parallel to the flow direction of the magma [Ellwood, 1978; Knight and Walker, 1988], although some models and

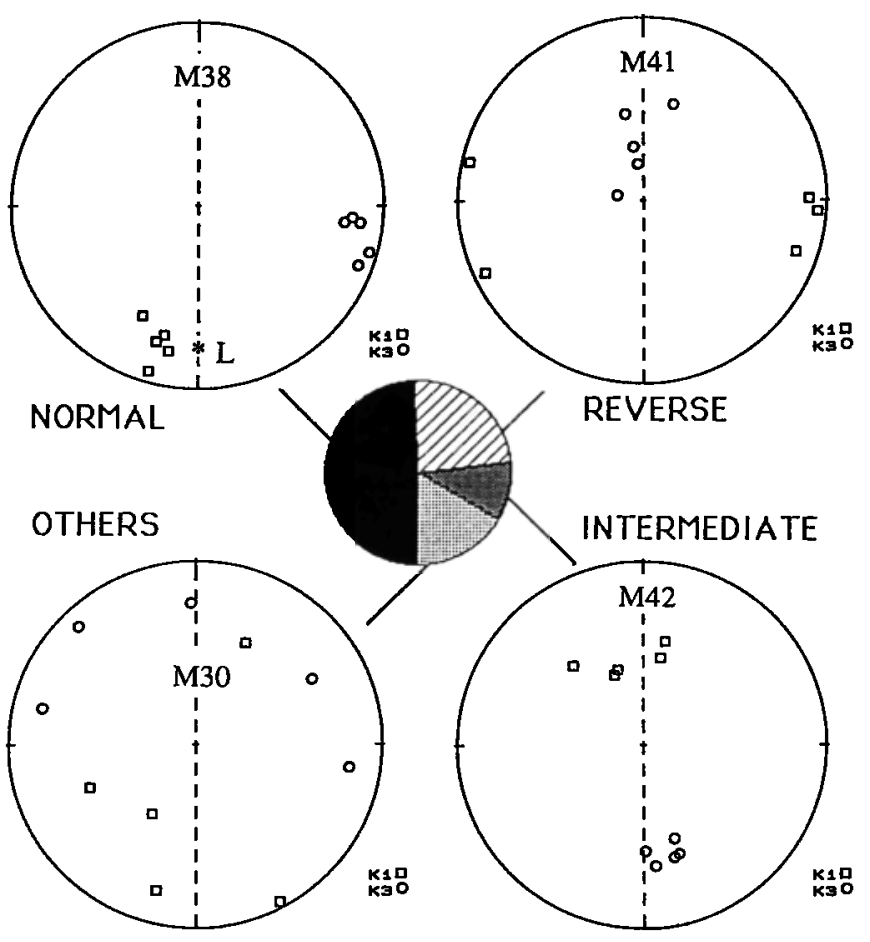

Figure 1. Examples of the four AMS fabric types encountered in the dikes from Oman, with their respective frequency in a pie diagram. Magnetic anisotropy data (maximum and minimum susceptibility axes, respectively, squares and circles) are plotted in "dike" coordinates, i.e., with the dike plane (dashed line) tilted to the vertical and rotated to a NS strike; $L$ indicates the flow line derived in this site from bubble elongation. AMS data presented in all the figures (except Figure 7) were obtained with the highsensitivity bridge KLY-2 manufactured by Geofyzika Brno.

case studies would suggest that $K_{2}$ should be parallel to the flow line instead of $K_{1}$ because of the "rolling" effect [Khan, 1962] (also reported for sedimentary currents by Rees and Woodall [1975]). This situation with $K_{3}$ perpendicular to the dike plane, referred to as "normal magnetic fabric" (because the magnetic axes correspond one by one to the petrofabric axes), is encountered in only $50 \%$ of the Oman dikes, as exemplified in Figure 1 (where the dike plane is vertical and NS in all cases). In $25 \%$ of the cases the inverse relationship is found between the expected petrofabric and the observed magnetic fabric, with $K_{1}$ perpendicular to the dike pole. Ten percent of the sites exhibit "intermediate magnetic fabrics," defined by the occurrence of $K_{2}$ axes perpendicular to the dike plane. The remaining "other" cases correspond to sites where anisotropy axes are scattered or where several types of magnetic fabric (normal, inverse, or intermediate) are found in the same dike. The purpose of the following two sections will be in particular to discuss the possible rock magnetic explanations of such abnormal magnetic fabrics, keeping in mind that they can also be due to "anomalous" petrofabric. In the case of our dikes the inverse magnetic fabrics are in fact also likely to be due to secondary processes that have erased the flow fabric, such as cooling stresses or hydrothermalism. 

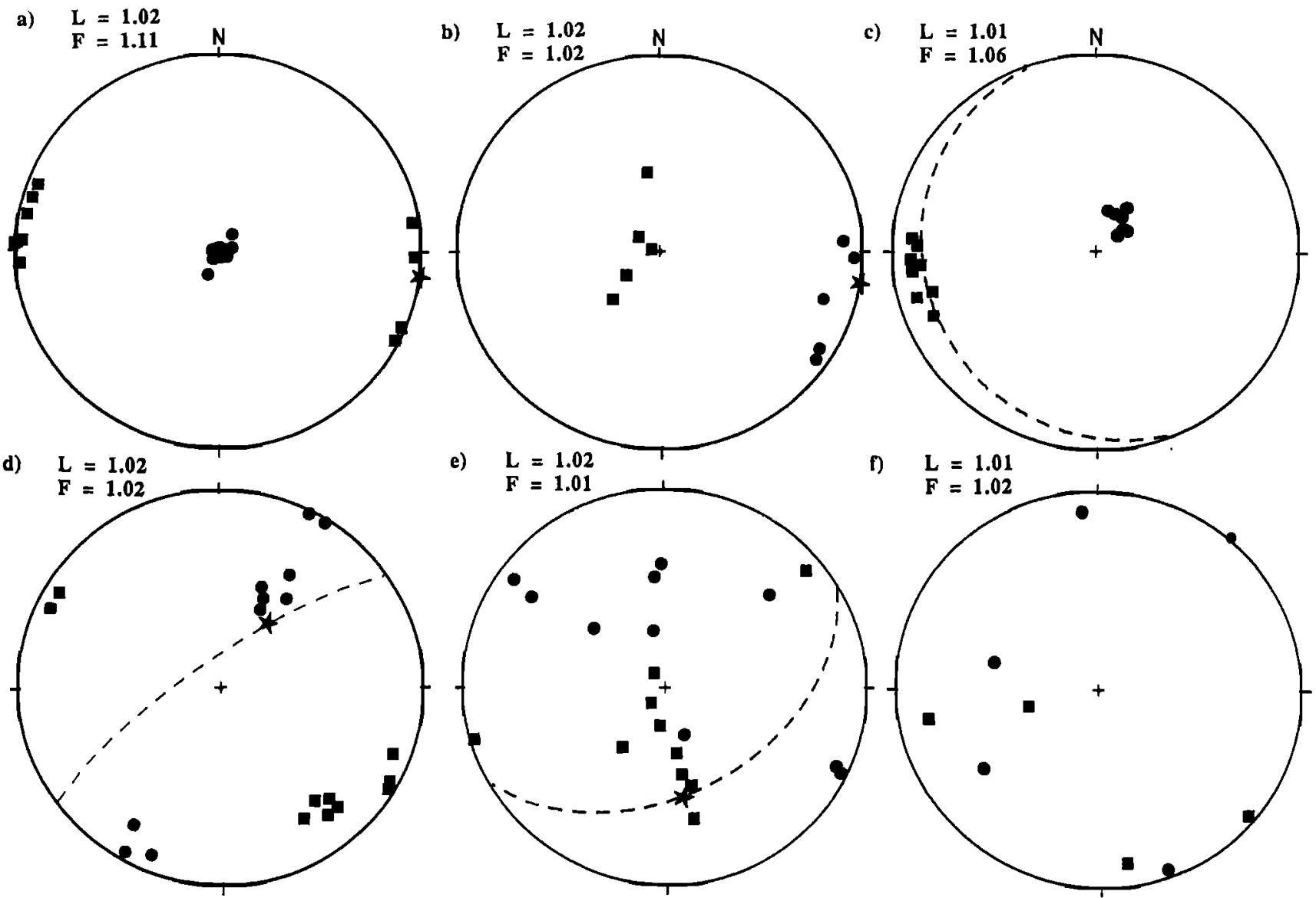

Figure 2. Stereoplots of AMS data, with average $L$ and $F$ values, from individual sites in various rocks whose susceptibility is due to paramagnetic minerals according to high-field measurements: (a) phyllosilicate-rich beds from a western alpine schist; (b) carbonate-rich beds from the same site [after Rochette, 1988a];

(c) biotite-bearing facies from the Everest leucogranite;

\section{MINERALOGICAL ORIGIN OF INVERSE MAGNETIC FABRICS AND THEIR IDENTIFICATION}

\subsection{Matrix Minerals}

Examples of matrix minerals whose preferred orientation lead to a normal magnetic fabric have been listed by Hrouda [1982]. These include phyllosilicates such as chlorite or biotite, as well as pyroxenes and amphiboles (see Table 1). Crystallographic control of both susceptibility and grain shape results in maximum (minimum) susceptibility along the long (short) dimension of such particles. For example, in an alpine schist whose susceptibility is entirely due to paramagnetic phyllosilicates the $K_{3}$ axes appear clustered around the pole of schistosity (vertical in Figure $2 a$ ) and the $K_{1}$ axes are parallel to the measured stretching lineation in the rock. However, interbedded limestone levels show the opposite relationship (Figure $2 b$ from Rochette [1988a]). Study of the magnetic mineralogy revealed that the susceptibility of these limestones is carried by paramagnetic ironbearing calcite or dolomite. Measurements on single crystals of iron-bearing carbonates including siderite [Rochette, 1988a] have shown that the $c$ axis (the revolution axis of the (d) tourmaline-bearing facies from the same massif; (e) mixed facies; $(f)$ cordierite- and biotite-bearing granite from Spain [after Amice, 1990]. Structural foliation (horizontal in Figures $2 a$ and $2 b$ ) is indicated by dashed lines, structural lineation when visible is indicated by a star.

rhombohedral structure) of the crystal is the axis of maximum susceptibility. Experimental deformation of calcite aggregates [Owens and Rutter, 1978] as well as X ray texture goniometry in naturally deformed marbles [Ihmlé et al., 1989] demonstrates that $c$ axes of carbonates tend to cluster around the flattening axis, thus explaining why $K_{1}$ appears perpendicular to schistosity in our case. Iron-bearing carbonates can be easily detected in a limestone by staining a thin section with potassium ferricyanide. Inverse magnetic fabric can be attributed to such minerals by establishing that the susceptibility is of paramagnetic origin, i.e., by highfield or low-temperature measurements. Usually, at least one structural element (foliation or lineation) is measurable and can be compared with $K_{1}$ and $K_{3}$ orientations. Once an inverse relationship has been demonstrated, the AMS results can be reliably interpreted in terms of petrofabric. The meaning of $F$ and $L$ are exchanged; a planar fabric is now characterized by good grouping of $K_{1}$ axes, and a value of $L \geqslant F$ (e.g., Figure $2 b$ ). Such inverse magnetic fabrics due to carbonates are probably mainly encountered in deformed metamorphic limestones [Rochette, 1988a; Ihmlé et al., 1989], although Rochette [1988a] also described an example from a siderite- 
TABLE 1. Selected AMS Data for Rock-Forming Minerals

\begin{tabular}{|c|c|c|c|c|c|}
\hline Mineral & Symmetry & Type & $K_{m}$ & $P$ & Reference \\
\hline & & \multicolumn{4}{|c|}{ Diamagnetic } \\
\hline Quartz & 0 & $\cdots$ & -14.5 & $<1.01$ & $1,2,13$ \\
\hline Calcite & lc & $\begin{array}{l}N(C) \\
\text { Parame }\end{array}$ & $\begin{array}{c}-13.0 \\
\text { agnetic }\end{array}$ & 1.13 & 1,2 \\
\hline $\begin{array}{l}\text { Biotite } \\
\text { Other }\end{array}$ & 1c & $N(C S)$ & $1-3$ & 1.35 & $2,3,4,5$ \\
\hline phyllosilicates & lc & $N(C S)$ & $0.05-1$ & $1.2-1.35$ & $2,3,5$ \\
\hline Pyroxenes & 4 & $N(S) ?$ & $0.5-5$ & $1.2-1.4$ & 2 \\
\hline Amphiboles & 4 & $N(S) ?$ & $0.5-5$ & $1.08-1.3$ & 2 \\
\hline Riebeckite & la & $?$ & 2.6 & 1.16 & 0 \\
\hline Orthoferrosilite & $1 \mathbf{a}$ & $?$ & 5 & 1.21 & 14 \\
\hline Staurolite & $2 b$ & $?$ & 0.8 & 1.06 & 0 \\
\hline Garnet & 0 & $\cdots$ & 3 & 1.001 & 0 \\
\hline Tourmaline & 1c & $I(S)$ & 0.9 & 1.12 & 0 \\
\hline Cordierite & $1 \mathrm{c}$ & $I(S)$ & 0.6 & $1.15-1.31$ & 0 \\
\hline $\begin{array}{l}\text { Siderite } \\
\text { Other Fe }\end{array}$ & $2 c$ & $I(C)$ & $3.8-4.2$ & 1.7 & 6 \\
\hline carbonates & $2 c$ & $\begin{array}{l}I(C) \\
\text { Ordere }\end{array}$ & ed $0.05-0.7$ & $1.08-1.45$ & 6 \\
\hline Goethite & lc & $I(S)$ & $1.3-5$ & $2 ?$ & $7,8,9$ \\
\hline Hematite & 3 & $N(C S)$ & $2-50$ & $2.5-100$ & $2,9,10$ \\
\hline Pyrrhotite & 3 & $N(C S)$ & $50-300$ & $>100$ & 9,11 \\
\hline Magnetite MD & 4 & $N(S)$ & $\leqslant 3000$ & $<5$ & 2,12 \\
\hline Magnetite SD & 3 & $I(S)$ & $\leqslant 1500$ & $\infty ?$ & 12 \\
\hline Magnetite SP & 4 & $N(S) ?$ & $\leqslant 5000$ & $\cdots$ & 12 \\
\hline
\end{tabular}

$K_{m}$ is in $10^{-3} \mathrm{SI}$, except for the diamagnetic minerals $\left(10^{-6}\right)$. Symmetry code: 0 , isotropic; 1 , uniaxial oblate; 2 , uniaxial prolate; 3 , triaxial oblate; 4 , triaxial prolate. For uniaxial, the symmetry is indicated by the crystallographic axis of revolution. Type code: normal $N$ or inverse $I$ with mechanism of preferred orientation either controlled by shape $S$ or by intracrystalline gliding during ductile deformation $C$. References: 0, unpublished or Rochette [1988b]; 1, Rochette [1987]; 2, Hrouda [1982]; 3, Ballet [1979]; 4, Zapletal [1990]; 5, Borradaile et al. [1987]; 6, Rochette [1988a]; 7, Hedley [1971]; 8, Rochette and Fillion [1989]; 9 , Dekkers [1988]; 10, Dunlop [1971]; 11, Rochette [1988a]; 12, Maher [1988]; 13, Hrouda [1986]; 14, Wiedenmann et al. [1986].

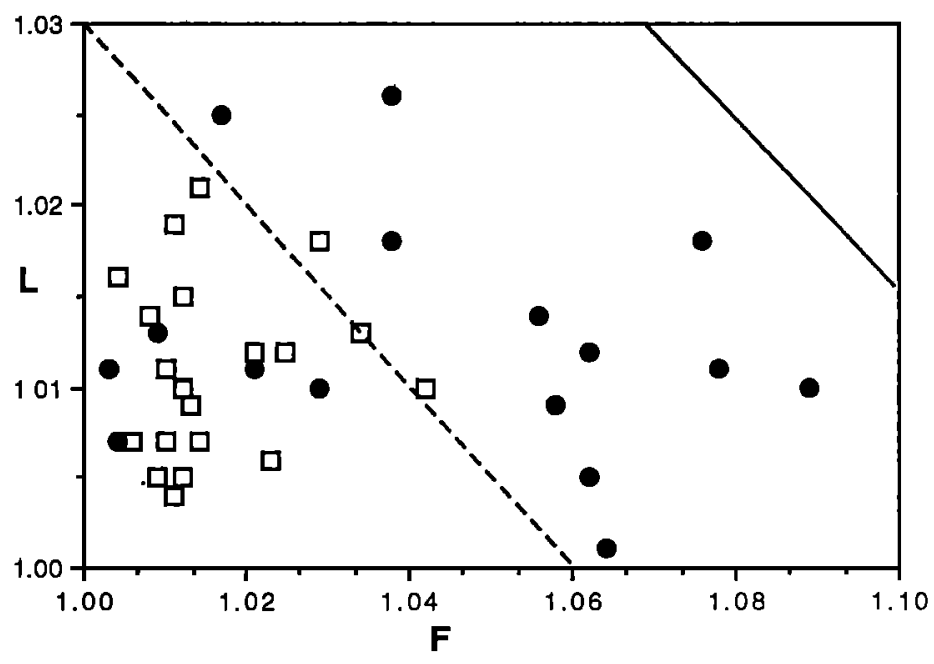

Figure 3. Anisotropy ratio $L$ versus $F$ for the Gangotri Himalayan leucogranite (redrawn from Scaillet, [1990]), with open and full symbols for the tourmaline and biotite facies, respectively. Solid and dashed lines indicate the maximum values for complete or $50 \%$ preferred orientation of tourmaline, respectively, according to the relationship (5) in section 3.3 . cemented sandstone where only compaction had occurred (see also Hirt and Gehring [1991]).

More recently, other matrix minerals have been found to produce inverse magnetic fabric. In a study of the high Himalayan Tertiary leucogranites [Rochette, 1988b; Scaillet, 1990] a large difference appeared between biotite-bearing outcrops (Figure $2 c$ ), which exhibit a well-defined normal fabric, and tourmaline-bearing outcrops where an inverse fabric is detected (Figure $2 d$ ). High-field measurements demonstrate that susceptibility, varying from $10^{-5}$ to $10^{-4} \mathrm{SI}$, is entirely due to matrix minerals. AMS measurements on various single crystals of tourmaline, which occur as rods elongated along the $c$ axis show minimum susceptibility along this axis (as already mentioned by Foex [1957, p. 278]). Therefore rocks whose AMS is dominantly due to tourmaline are expected to show $K_{3}$ parallel to the linear preferred orientation of tourmaline crystals and $K_{1}$ perpendicular to the foliation plane. This situation is well demonstrated in some of the Himalayan tourmaline facies samples where lineation and foliation are readily visible. Again, the significance of the anisotropy ratio is inverted. The fabric of these granites is dominantly planar, as shown by $L<F$ for the biotite facies (Figure 3 after Scaillet [1990]), while $L$ is similar or slightly larger than $F$ on the average for the tourmaline facies. The values of $L$ and $F$ are also consistently smaller for the tourmaline facies. This agrees well with single-crystal measurements: black tourmaline monocrystals of the kind present in those granites show $K_{m}$ around $9 \times 10^{-4} \mathrm{SI}$ and $P \approx 1.12$ in contrast to $P=1.35$ for biotite [Zapletal, 1990].

Thus when studying those granites where lineation orientation is the chief interest, the dominance of tourmaline or biotite in the susceptibility has to be determined in order to equate the structural lineation to $K_{1}$ or $K_{3}$. In several cases, visual and thin section inspection unfortunately reveal both of these minerals. Actually, such a site has been found to bear samples with normal and inverse magnetic fabric, within one $10-\mathrm{cm}$ block (Figure $2 e$ ). It thus appears desirable to find a rock magnetic method to differentiate between specific paramagnetic minerals. This has been attempted by using the variation of $K_{H F}$ at low temperature. Fitting by a CurieWeiss law, corrected for a diamagnetic contribution, allows calculation of the paramagnetic Curie temperature $\theta$, which is the intercept of the inverse susceptibility with the temperature axis (Figure 4). Our results for a tourmaline single crystal show that $\theta$ is $-10 \mathrm{~K}$ along the $c$ axis and $-1 \mathrm{~K}$ in the perpendicular plane. On the other hand, data on biotite monocrystals [Ballet, 1979] indicate $\theta$ values of 5 to $20 \mathrm{~K}$ and near-zero values in muscovite monocrystals. In fact, $\theta$ is a measure of the strength of the magnetic interactions (roughly increasing with increasing iron amount in the crystal) and of their type $(\theta<0$ for dominantly antiferromagnetic interactions) [e.g., Coey, 1988]. Inverse susceptibility curves (Figure $4 a$ ) on samples from the tourmaline and biotite facies of the Himalayan leucogranite, as well as on samples from purely muscovite-bearing Hercynian granites (see Figure 1 in the work by Rochette [1987] and Figure 4 in the work by Jover et al. [1989]) show $\theta$ values in very good agreement with the monocrystal values. Therefore this technique, al- 

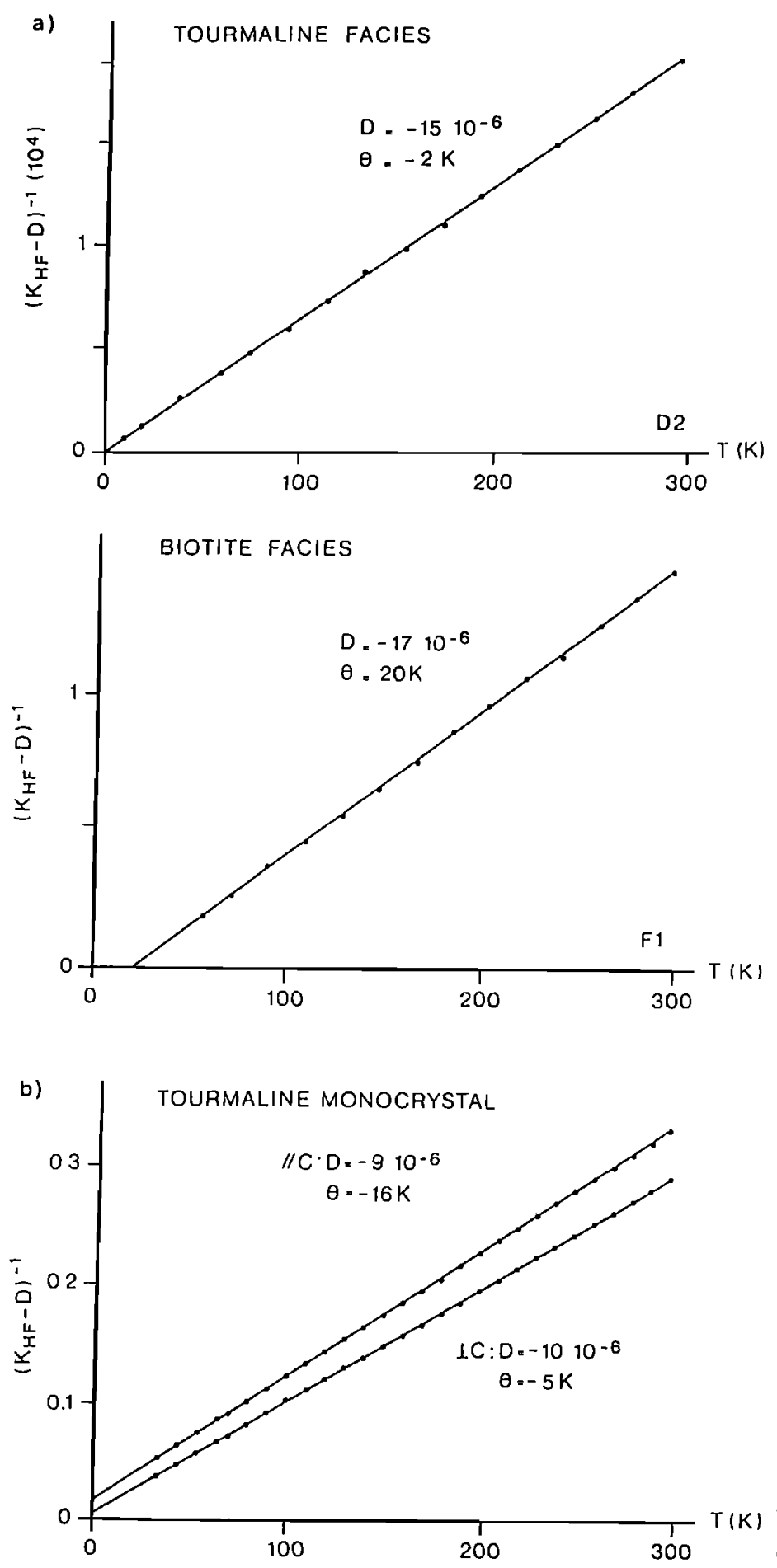

Figure 4. Inverse of high-field susceptibility $K_{H F}$ corrected for the diamagnetic term $D$ versus temperature for $(a)$ two samples of tourmaline- and biotite-bearing leucogranite from the Everest massif; (b) a tourmaline monocrystal parallel and perpendicular to the $c$ axis. Fitted $D$ and $\theta$ values indicated.

though it requires high precision to define an accurate $\theta$ value, seems to be able to distinguish different paramagnetic minerals.

In studying Hercynian granites from Spain, Amice [1990] was led to question the possible role of cordierite as a carrie of AMS in those rocks with typically paramagnetic susceptibility [Amice and Bouchez, 1989]. Cordierite occurs in these granites as rods elongated parallel to the $c$ axis in the orthorhombic system, and a preferred orientation of those rods was occasionally observed. AMS measurements on single crystals cut from the granite samples again show a minimum susceptibility parallel to the $c$ axis, with $P$ from 1.15 to 1.31 and $K_{m} \approx 6 \times 10^{-4} \mathrm{SI}$. Therefore inverse fabric may be expected again. In one cordierite-rich site (Figure $2 f$ ) the AMS results on four samples indeed show that the $K_{1}$ and $K_{3}$ axes are exchanged in two samples, indicating that normal fabric (due to biotite) and reverse fabric (due to cordierite) are coexisting in the samples.

To complete the list (see Table 1) of matrix minerals as possible carriers of inverse fabric, the antiferromagnetic oxihydroxide $\alpha \mathrm{FeOOH}$, i.e., goethite, must be mentioned. This mineral occurs usually as needles parallel to the $c$ axis, which is also the direction of spin alignment. Therefore, as observed on a single crystal by Hedley [1971], one can expect a minimum antiferromagnetic susceptibility along the needle axis. At room temperature the $P$ ratio observed by Hedley is 2.04 . Low-field susceptibility due to the weak ferromagnetic behavior of this mineral may change the situation for AMS but this contribution is probably negligible [e.g., Rochette and Fillion, 1989]. However, because of the very low mean susceptibility of goethite (about $2 \times 10^{-3} \mathrm{SI}$ ) compared to associated minerals such as maghemite, hematite, or many paramagnetic minerals, an AMS carried by goethite will probably be very rarely encountered.

\subsection{Ferromagnetic Minerals}

Among the remanence-carrying minerals, hematite, pyrrhotite, and multidomain (MD) magnetite (or related cubic iron oxides) are well known to produce normal fabric [e.g., Hrouda, 1982]. On the other hand, Daly [1970], O'Reilly [1984, p. 70], and Stephenson et al. [1986] have pointed out that single domain (SD) uniaxial prolate grains of magnetite have a zero susceptibility along their easy axis of magnetization, i.e., their long axis. The resulting inverse AMS fabrics have been exemplified in limestones [Rochette, 1988a], in samples with synthetic SD maghemite, in basaltic rocks [Potter and Stephenson, 1988], and more recently in experimentally deformed synthetic samples [Borradaile and $\mathrm{Pu}$ umala, 1989]. As recently reviewed by Jackson [1991], the best way to detect such inverse fabric is to study the anisotropy of anhysteretic remanence (AAR). As SD grains have their ARM parallel to the easy axis, the AAR fabric should be normal [e.g., Potter and Stephenson, 1988].

However, as found in several cases including the dikes of Oman (see also Rochette [1988a]; and Aubourg [1990]), the AAR fabric appears similar to the anomalous AMS fabric (e.g., Figure $5 a$ ). This may be related to an abnormal preferred orientation of the magnetite grains or to a specific behavior of pseudo single domain (PSD) grains, which are characterized by a few domain walls pinned on crystalline defects. Indeed, it is not impossible from the theoretical point of view that some kind of PSD grains may have a minimum 
axis parallel to their long dimension both for AMS and AAR: if the remanent magnetization of the pinned domain walls is larger than that due to the different sizes of the domains, it will account for inverse AAR, while for AMS, such PSD grains could exhibit the same behavior as SD grains. However, whether this situation may be encountered in nature remains to be demonstrated.

In this overview of the grain size dependence of the intrinsic AMS of uniaxial magnetite grains, one may also consider the case of superparamagnetic (SP) grains. A SP grain has a very high susceptibility along its easy axis, because thermal activation allows the spontaneous moment to jump freely from one to the other equilibrium position. On the other hand, the perpendicular susceptibility is similar to that of an SD grain as the spontaneous moment has to be rotated away from the easy axis. Therefore a uniaxial SP grain should show a normal AMS fabric. Whether SP grains are able to show any preferred orientation in nature remains speculative.

\subsection{The Problem of Intermediate Fabrics}

When dealing with inverse fabrics, one often encounters intermediate cases, i.e., with $K_{2}$ perpendicular to the foliation plane as exemplified in Figure 1, or samples that interchange their principal axes with respect to other samples from the same site [Rochette, 1988a; Aubourg, 1990; Rochette et al., 1991]. Another example is found in Figure $5 b$, which shows the AMS data from a shale-limestone site from the Upper Jurassic of the Western Alps in a folded area with no schistosity [Aubourg, 1990]. All samples have apparently normal fabric with $K_{3}$ perpendicular to bedding, except some samples from a single limestone bed which tend to be intermediate with $K_{3}$ and $K_{1}$ within the bedding plane. The more shaly samples yield NS $K_{1}$ axes (the observed structural lineation parallel to fold axis), while the limestone samples have EW $K_{1}$ axes. The EW magnetic lineation could be another undetected structural lineation [Aubourg et al., 1991] or the artifact of an exchange between $K_{1}$ and $K_{2}$ axes, the NS direction being the truly normal lineation for the whole site. Another indication of abnormal fabric is that the AMS ellipsoid shape is prolate or near neutral for the samples with EW lineation or intermediate fabric, while the other samples have strongly oblate shapes. AAR measurements, with a peak alternating field of $100 \mathrm{mT}$, on these limestones duplicate the AMS results in almost perfect detail for each sample (only $K_{3}$ axes appear a bit more dispersed, Figure $5 b$ ). ARM ellipsoids are almost all prolate, as the susceptibility ellipsoids are, with $P$ values not larger than 1.03 . Thus we can rule out anomalous AMS in these rocks as due to the "SD" effect.

Hysteresis measurements indicate a predominance of finegrained ferrimagnetic material in these samples. The ratio of saturation remanence to saturation magnetization is approximately 0.15 ; according to the empirical framework of Day et al. [1977], this indicates a mean magnetic grain size within the PSD range. Thus both anomalous petrofabric (due to mechanical contrast between the carbonate and surround-
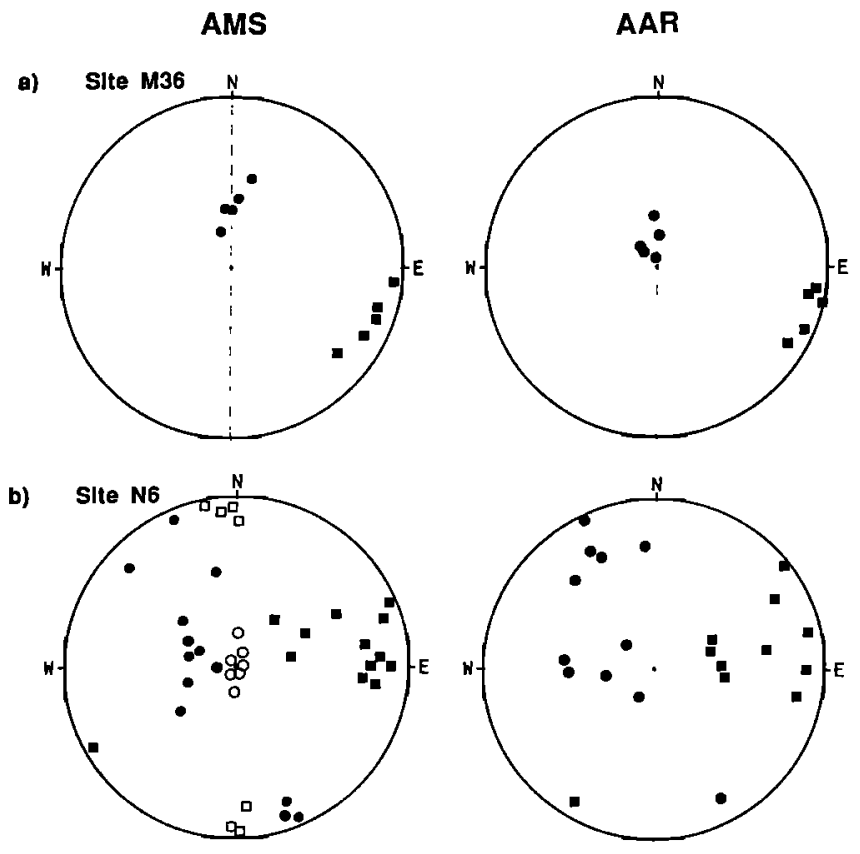

Figure 5. Comparison of AMS and AAR (measured in Minneapolis with a cryogenic magnetometer and ARM acquired in 100$\mathrm{mT} \mathrm{AF}$ and 0.1-mT bias field; see McCabe et al., [1985]) maximum and minimum directions: (a) for a dike with inverse AMS fabric; (b) for a shale-limestone site from the Upper Jurassic of Western Alps with the bedding plane corrected to the horizontal (site N6 after Aubourg [1990]). Shale samples appear in open symbols.

ing shaly layers or to a specific deformation mechanism such as selective dissolution of calcite grains under deviatoric stresses) and anomalous magnetic fabric (due to particular PSD grains) may possibly explain the present data set.

Two paramagnetic silicates, both in the monoclinic crystallographic system, have been found to exhibit an AMS ellipsoid neither related to the normal nor the inverse situation: staurolite and riebeckite (a Na and $\mathrm{Fe}^{3+}$ rich amphibole), which crystallize as rods elongated along the $c$ axis. The AMS measured on selected monocrystals is uniaxial prolate with $K_{1}$ parallel to the $b$ axis in staurolite and uniaxial oblate with $K_{3}$ parallel to the $a$ axis in riebeckite. The latter situation is in fact also encountered in the Fe-rich orthopyroxene (orthoferrosilite) studied by Wiedenmann et al. [1986], in contradiction with pyroxene data reported by Hrouda [1982] (see Table 1). Therefore the preferred orientation of the long axis (i.e., $c$ axis) of such grains does not produce a simple normal or inverse magnetic fabric, but the resulting AMS depends on the $b$ or $a$ axes preferred orientation (see Table 1). It may produce a complex relationship between AMS and petrofabric with a possibility for an intermediate magnetic fabric.

However, it does not seem possible to find a single mineralogical origin for intermediate magnetic fabrics. On the other hand, their close association with inverse or normal magnetic fabrics, often in the same site, suggests an explanation by a mixing of different mineralogical components. This will be discussed in the following section 3.2. 


\section{OTHER EFFECTS OF MINERALOGY ON THE SUSCEPTIBILITY ANISOTROPY}

\subsection{Quantitative Significance of the Anisotropy Ratio in a Two-Mineral System}

The effects of variable mineralogical composition on AMS ratios have been considered in a number of previous studies [e.g., Borradaile, 1987; Hrouda, 1987; Rochette, 1987]. These studies were generally concerned with the widely encountered case where susceptibility is due to more than one mineral, with coaxial normal fabrics but different anisotropy ratios. It is obvious that if the proportion between these contributions changes in a formation, the global anisotropy ratio will show variations independent of strain intensity but related to composition, i.e., lithology. One should expect a correlation between $K_{m}$ and $P$ if the different contributions have different $K_{m}$ as well as $P$ values as exemplified in Figure 6. The different examples gathered in that figure, from pyrrhotite-bearing schists [Hrouda, 1987; Rochette, 1987] (see also Fuller [1963], and Borradaile and Sarvas [1990], for very similar $P$ versus $K_{m}$ relationship in such rocks), magnetite-bearing granitoids [Damm, 1988], and basaltic dikes [Rochette et al., 1991], clearly demonstrate the wide occurrence of the control of anisotropy ratio by the proportion of ferromagnetic versus paramagnetic contribution to the susceptibility. In such plots the increasing trend of $P$ values mainly appears for $K_{m}>3-510^{-4} \mathrm{SI}$ and $P>1.2$ (for strongly deformed rocks). These limits correspond to the usual upper limits of the paramagnetic contribution [Rochette, 1987].

For a two-component ( $A$ and $B$ ) system a formula relating $P$ and $K_{m}$ for the rock as a function of the anisotropy degree of each component $\left(P_{A}\right.$ and $\left.P_{B}\right)$ has been proposed [Rochette, 1987] in the case where the contribution $K_{A}$ of $A$ component to the mean susceptibility is constant (i.e., independent of the fraction $f$ of the $B$ component):

$$
\begin{aligned}
P= & {\left[K_{m}\left(P_{A}+1\right) P_{B}-K_{A}\left(P_{B}-P_{A}\right)\right] /\left[K_{m}\left(P_{A}+1\right)\right.} \\
& \left.+K_{A}\left(P_{B}-P_{A}\right)\right]
\end{aligned}
$$

The assumption made is valid if $A$ is the diamagnetic contribution and $B$ is a variable paramagnetic or ferromagnetic contribution or if $A$ is a constant matrix term and $B$ is a ferromagnetic mineral with large susceptibility but small amount $(f<0.05)$. In such cases we can equate $K_{m}$ to $K_{A}$ $+f K_{B}$. To derive (1), $f$ and $K_{B}$ were eliminated from the basic equations $\left(K_{t}=K_{A i}+f K_{B i}\right)$ using the relationships for neutral ellipsoids; For example, $K_{m}=\left(K_{1}+K_{3}\right) / 2=K_{2}$. Similar relationships were derived for purely oblate or prolate ellipsoids but computations showed that the resulting curves are in fact shape independent for small $f$ values. When such assumptions are not valid; i.e., when we have $K_{i}=(1-$ $f) K_{A t}+f K_{B i}$, Borradaile and Sarvas [1990] proposed the following relationship:

$$
P=\left[f K_{B 1}+(I-f) K_{A 1}\right] /\left[f K_{B 3}+(I-f) K_{A 3}\right]
$$

The first proposed law (1), which uses more readily meas- urable parameters, was found to fit quite well the data from a weakly magnetic granite with a diamagnetic isotropic $\left(P_{A}\right.$ $=1$ ) contribution and a variable paramagnetic phyllosilicate amount, responsible for the anisotropy [Rochette, 1987; see Hrouda, 1986]. It was possible to correct the anisotropy ratio to get a value independent of the phyllosilicate amount. In examples such as in Figure 6 it is possible to qualitatively fit the $P$ versus $K_{m}$ relationship using both laws.

Although the section on inverse fabrics emphasized the extreme case of complete inversion of principal axes, a more subtle and probably far more common effect associated with the presence of "inverse" minerals is simply a reduction in the degree of anisotropy [see Potter and Stephenson, 1988]. This may be an important source of error in "strain gauge" applications of AMS. A possible example of this effect can be seen in the study of mylonites from the Brevard zone by Goldstein and Brown [1988]. They observed that mean susceptibility decreases with increasing intensity of mylonitic foliation and interpreted it in terms of decreasing grain size of the magnetite grains. This would imply an increasing proportion of SD grains. They also observed an associated decrease in anisotropy degree; this could plausibly be the result of coexisting normal and inverse anisotropies, due to MD and SD particles, respectively.

It is therefore quite obvious that direct quantitative use of AMS is not possible when the susceptibility is not due to a single mineral or even a single grain size fraction in the case of magnetite, a possibly quite rare situation in rocks. To overcome this problem without using a more specific anisotropy technique such as high-field (for the matrix minerals) or remanence anisotropy (for the ferromagnetic fraction), Henry [1983] has proposed an indirect method for the case of an AMS with two contributions, one called matrix and the other ferromagnetic. An application of this method, based on a correlation between diagonal terms $K_{i i}$ of the susceptibility tensor and mean susceptibility $K_{m}$ on the site level, is shown in Figure 7, which illustrates AMS results from Proterozoic slates of northern Minnesota [Johns, 1990]. Henry's method allows one to derive from the observed linear correlations between $K_{i}$ and $K_{m}$ the matrix and ferromagnetic susceptibility tensors, with an algorithm based on the following assumptions: the matrix and ferromagnetic fabric are constant (in orientation and intensity) within the site and the variation of $K_{m}$ and $K_{i}$ is only due to a variable amount of ferromagnetic grains while the matrix contribution remains constant. The data of Figure 7 yield a good linear correlation that allows derivation of apparently significant matrix and ferromagnetic susceptibility mean tensors for the site, with quite different anisotropies. While $L$ values are similar for the matrix, ferromagnetic, and AAR (ARM measured in 100mT peak alternating field) tensors, the $F$ values are 1.07 , 1.92 , and 1.18 , respectively. In particular, the computed ferromagnetic susceptibility $F$ ratio appears to be unrealistically high, compared to the AAR ratio.

The interpretation given by the model is both nonunique and testable. In particular, it implies that the ratio of ferromagnetic to total low-field susceptibilities increases with mean susceptibility, from a value near zero up to about $30 \%$ for 
(a)

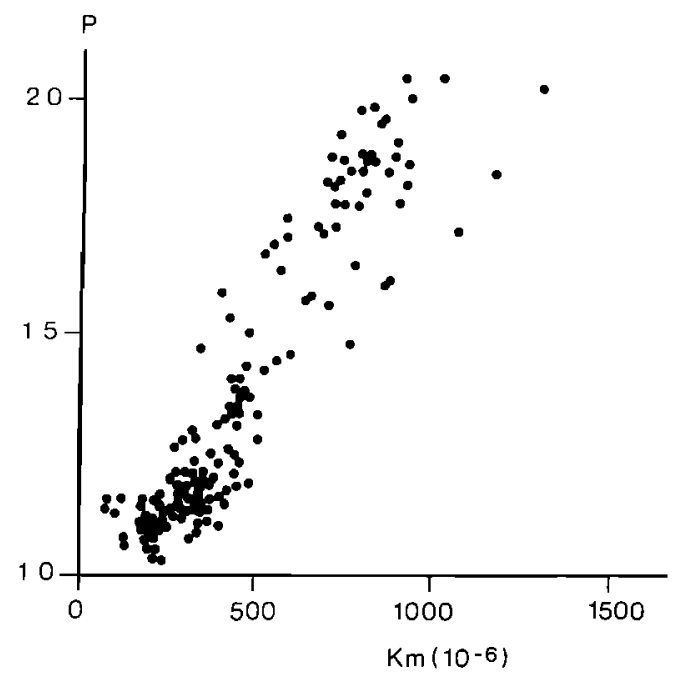

(c)

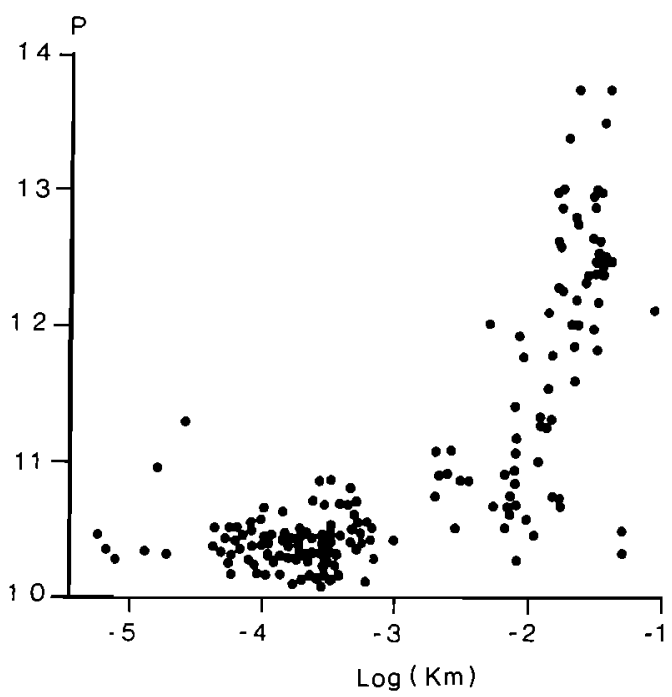

Figure 6. $P$ versus $K_{m}$ plots for various regional studies: $(a)$ and (b) pyrrhotite-bearing schists from the Carpathians after Hrouda [1987] and from the Swiss Alps after Rochette [1987], respectively; (c) granitoids from the hercynian chain [Damm, 1988]; (d) magnetite-bearing basaltic dikes from Oman [Rochette et al.,

the highest susceptibility samples (Figure 7a). However, direct measurement of this ratio using high-field susceptibility measurements shows that it remains practically zero $(\leqslant 2 \%)$ on the whole range of $K_{m}$; in those slates, susceptibility appears in fact entirely of paramagnetic origin on the whole range of $K_{m}$ values, thus ruling out the conclusions derived from Henry's model. The apparent "ferromagnetic" fabric derived from the seemingly conclusive correlation in Figure 7 has no physical significance, while the "matrix" fabric is just some sort of average of the AMS data.

In fact, it can be concluded that results of Henry's method can only be trusted if its basic assumption, i.e., constant matrix contribution and variable ferromagnetic amount, is (b)

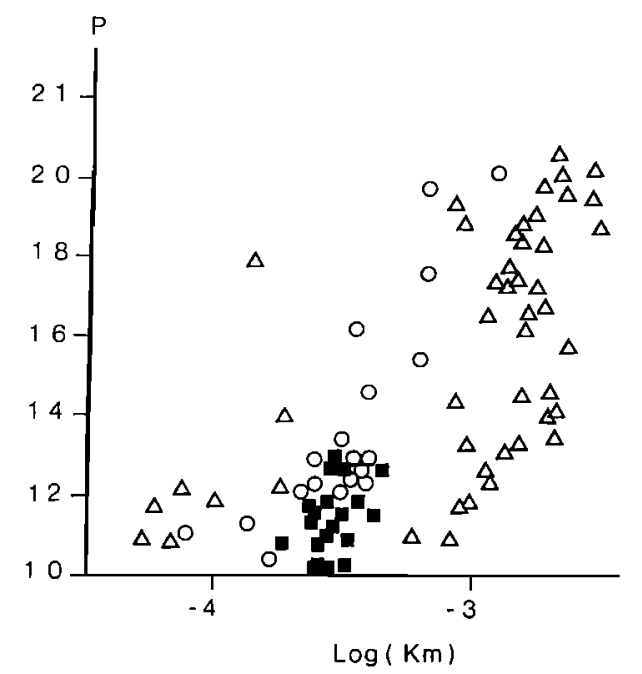

(d)

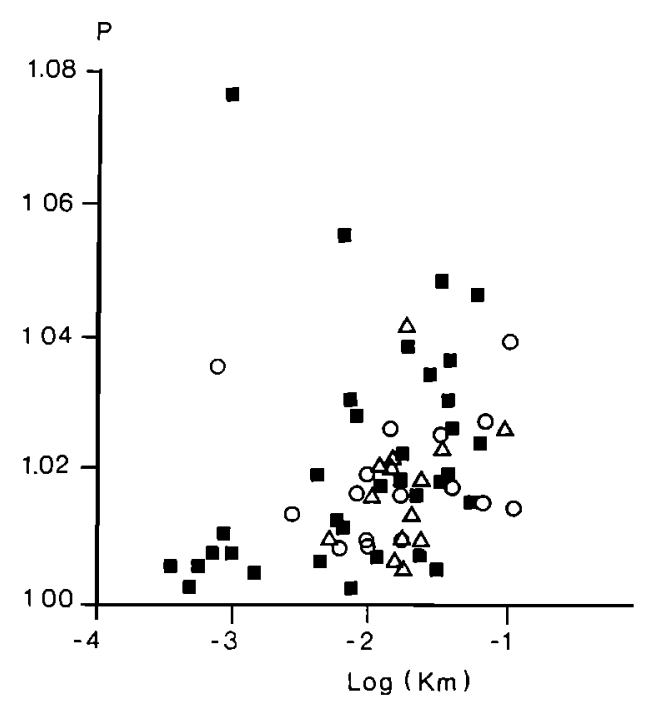

1991]. In Figure $6 b$, samples with pyrrhotite not detected, present, and abundant are shown with squares, open circles, and triangles, respectively. In Figure $6 d$ the site mean values for normal, reverse, and other fabric types appear as squares, open circles, and triangles, respectively.

verified by an independent method such as high-field measurements. Unfortunately, all rock formations with mixed contributions to AMS and variable $K_{m}$ that have been studied so far with this technique [e.g., Rochette, 1987] revealed a variability of the matrix component as large as the one of the ferromagnetic component.

\subsection{A Model for Intermediate Magnetic Fabrics}

To find a possible explanation for the occurrence of these abnormal but not truly inverse AMS fabrics often associated with inverse fabric, where $K_{2}$ exchanges its direction with $K_{1}$ or $K_{3}$, let us consider what happens for a mixture of two minerals with coaxial petrofabrics, but normal and inverse 


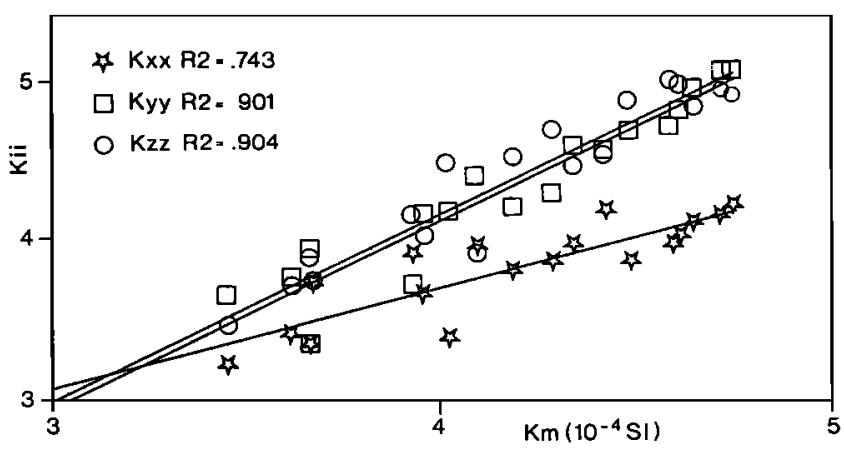

Figure 7. Plot of principal susceptibilities $K_{u}$ versus mean susceptibility $K_{m}$ [after Johns, 1990] in Proterozoic metasediments from Minnesota, according to the method of Henry [1983].

magnetic fabrics, for example, either MD and SD magnetite or some matrix minerals. The following models start from the example of Figures $2 a$ and $2 b$ with a petrofabric defined by a horizontal foliation (perpendicular to the $z$ axis) and an EW ( $y$ axis) lineation. The mixing parameter $p$ is defined as the proportion of the inverse component in the mean susceptibility. It is possible to calculate the susceptibilities along the NS, EW, and vertical directions $\left(K_{x}, K_{y}, K_{z}\right)$ as a function of $p$ and given values for the principal susceptibilities of both components, chosen to give $K_{m}=1$ (Figure 8). As both end-member magnetic fabrics reflect the same petrofabric foliation and lineation, we have for $p=0$ a maximum $K_{y}$ and a minimum $K_{z}$ (normal magnetic fabric), while the opposite (reverse magnetic fabric) holds for $p=1$. Stereonets on the right of the figure illustrate the resulting orientations of principal AMS axes.

In Figure $8 a$ there is a unique $p$ value producing a fully isotropic point $\left(K_{x}=K_{y}=K_{z}\right)$ and normal or inverse magnetic fabric on each side. This situation occurs when the shapes of the end-member ellipsoids are exactly "inverse," for example, one oblate and the other prolate or both neutral as in Figure 8a. Formally, it corresponds to $E_{n}=\left(L_{n}-1\right) /$ $\left(F_{n}-1\right)=\left(F_{1}-1\right) /\left(L_{i}-1\right)=E_{i}$, where the subscripts $n$ and $i$ refer to the normal and inverse components. This condition may often not be met in rocks. As discussed by many previous authors [Owens, 1974; Hrouda, 1982; Rochette, 1987; Borradaile, 1987], the AMS due to an individual mineral depends upon both its orientation distribution and its characteristic anisotropy. Thus the symmetric situation described above could arise only when the susceptibility is due to two minerals with similar shape-orientation distributions and similar but inverted shapes of their intrinsic susceptibility ellipsoids. However, this is clearly a special case. Thus it is appropriate to introduce some asymmetry in the end-member magnetic fabric shapes for our mixing model.

Figures $8 b$ and $8 c$ show the AMS behavior resulting from $E_{n}>E_{i}$ (i.e., the normal component is less oblate than the inverse component is prolate) and $E_{n}<E_{i}$, respectively. It is easy to observe from the evolution of $K_{x}, K_{y}, K_{z}$ that four different stages appear: normal and inverse end-members, one truly intermediate (i.e., $K_{z}$ being the intermediate di- rection), and one that can be named as a "false" normal or inverse magnetic fabric, because it looks normal (or inverse) from the point of view of $K_{z}$ but the horizontal axes are not in the expected positions. In particular, the model of Figure $8 c$, with a stage where $K_{3}$ is vertical but $K_{1}$ is perpendicular to lineation (false normal case), exhibits the same sequence of fabrics as the natural example of Figure $5 b$, where what could be interpreted as normal, false normal, and intermediate fabrics coexist in the same outcrop. In that case the two components are likely to be due to MD and SD magnetite. In particular, the ratio ARM $/ K_{m}$ increases from normal to false normal and intermediate samples, while the shape, strongly oblate in normal samples, becomes prolate or neutral in false normal and intermediate samples. However, a complex petrofabric may as well explain the results of Figure $5 b$.

Using partial ARM anisotropies, Jackson et al. [1989a] were able to demonstrate in a compacted shale that the coarser soft grains have a much more oblate AAR fabric than the finer higher coercivity grains, which have neutral shape in that case. Assuming that the finer fraction has an inverse AMS fabric, we obtain the case of Figure $8 c$; in fact, this case with false normal stage is probably more likely to occur.

If such false normal magnetic fabrics are not rare, it strongly complicates the interpretation of weak magnetic lineations such as those found in the Western Alps [Aubourg et al., 1991]. The test of $K_{3}$ perpendicular to foliation is often used as a criterion for evaluating the reliability of $K_{1}$ as a structural lineation indicator; the modeling results above show that this criterion may be misleading. Such problems again strongly indicate the need for additional rock magnetic information in interpreting AMS results.

The intermediate magnetic fabrics encountered in the basaltic dikes of Oman (Figure 1) may be well explained by the present mixing model, the normal end-member being the primary flow fabric and the inverse end-member being the secondary fabric with $K_{1}$ perpendicular to the dike plane. In fact, several sites are found with normal and intermediate or reverse and intermediate samples in the same dike. The proportion of normal:reverse:intermediate dikes, about $5: 2: 1$, is also similar to what can be derived from the model: endmembers are more likely to occur than the intermediate stages of the mixing model. This model also predicts a lower anisotropy ratio in the intermediate case, as found in the dike data set (Figure $6 d$ and Rochette et al [1991]).

\subsection{Symmetry of Magnetic Fabric Versus Mineralogy}

An additional mineralogical effect that has not been explicitly discussed is the sensitivity of AMS symmetry (prolate versus oblate) to mineralogical composition. An extreme example of this effect can be seen in the case of a mixing between normal and inverse magnetic fabrics. In the model of Figure $8 a$, the end-member ellipsoids and mixtures for all values of $p$ are neutral and only the degree of AMS varies with $p$. However, in the more realistic models $b$ and $c$ the AMS symmetry changes drastically with $p$. For example, in Figure $8 c$ the shape of the ellipsoid evolves from strongly oblate to purely oblate, then through neutral to purely prolate, 

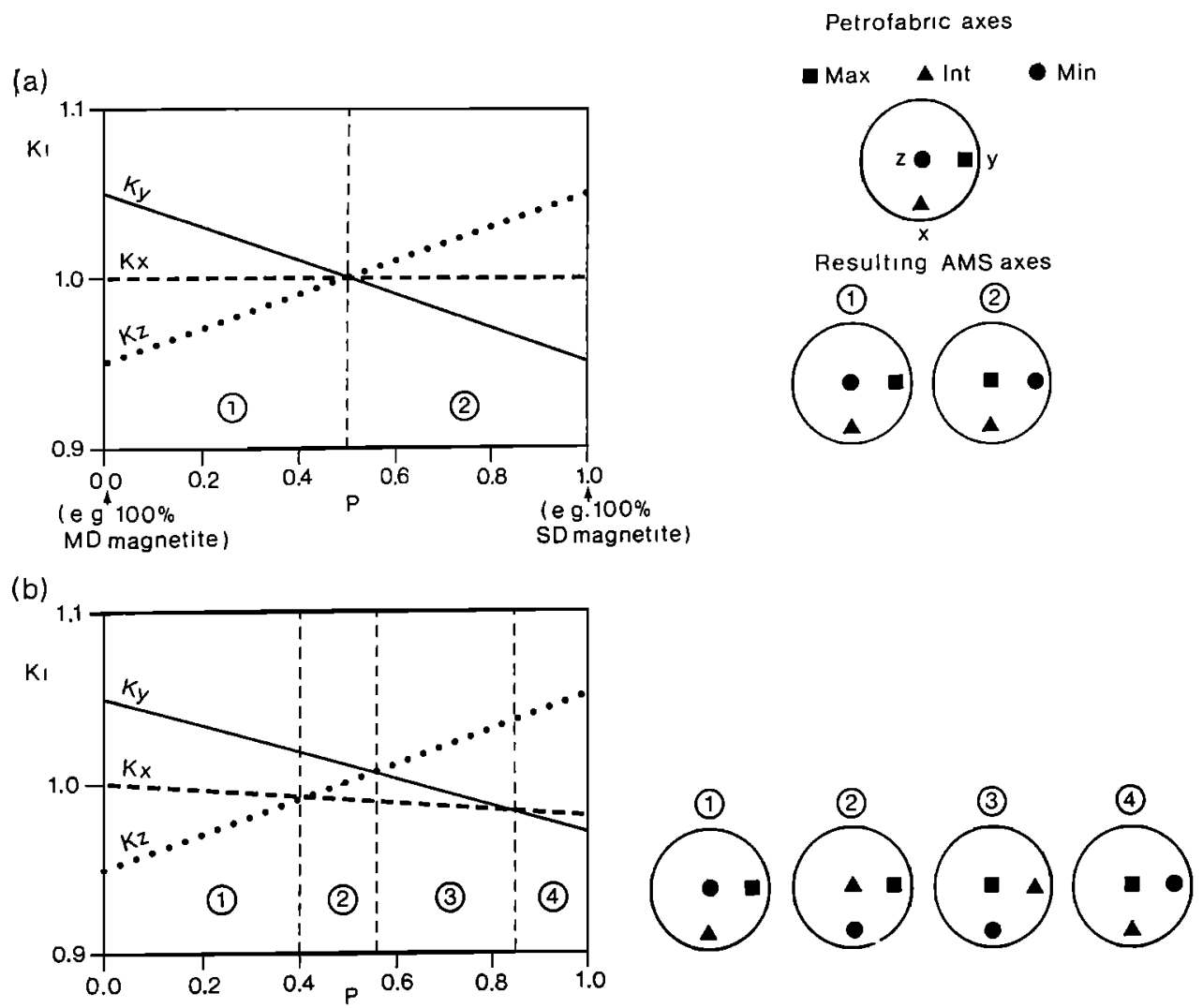

(c)
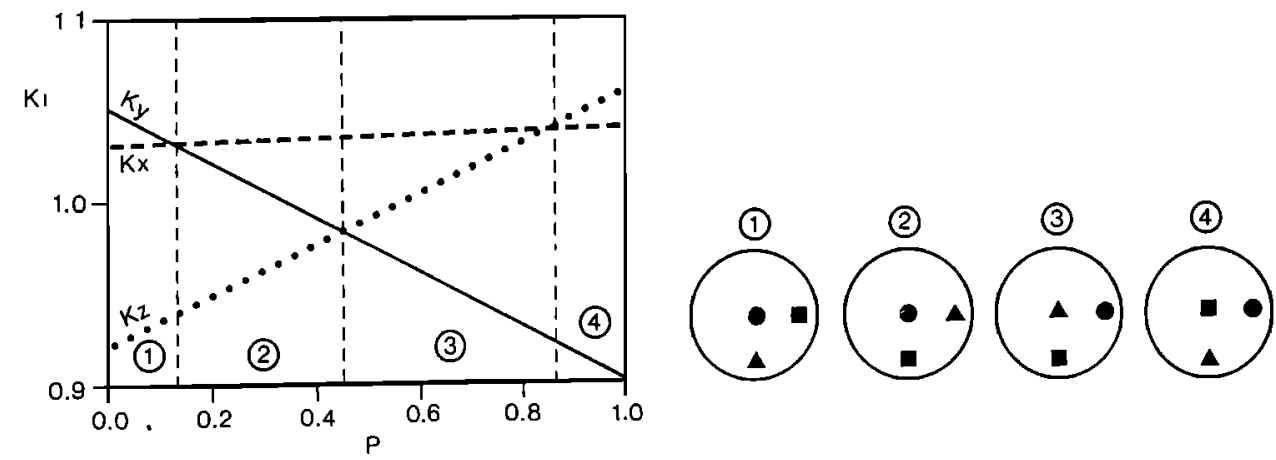

Figure 8. Model of normalized principal susceptibilities along $x$, $y, z$ for a mixture of MD and SD grains with coaxial petrofabric (grain alignment along $y$ and pole of foliation along $z$ as indicated in the first stereonet) versus the proportion $p$ of SD in the total

susceptibility. Three different relative shapes of the SD and MD ellipsoids are represented (see text). Stereonets on the right show the resulting $K_{1}, K_{2}$, and $K_{3}$ directions (same convention as in Figure 1) for the different domains defined by the intersections of the lines.

and finally back through neutral to purely oblate. Note that this sequence strongly resembles the pattern commonly associated with progressive deformation of sedimentary rocks: bedding plane foliation, lineation along the bedding-cleavage intersection, and finally cleavage plane foliation.

A more common effect may be produced by the different ellipsoidal symmetries associated with different minerals. Consider an initially isotropic rock undergoing plane strain, so that the $K_{1}$ axes of individual particles rotate toward the stretching direction and $K_{3}$ axes rotate toward the shortening direction. If these axes rotate at the same rate, then the AMS symmetry of the rock is entirely determined by those of the source particles: magnetically oblate particles such as phyl-

losilicates will result in an oblate AMS and conversely for prolate mineral grains. For example, magnetic fabric due to oblate minerals will be more sensitive to planar than linear deformation regimes. This must be taken into account when considering the variation of anisotropy degree $P$ of the rock. For purely oblate grains with a mineral anisotropy degree $P_{m}$ the maximum possible anisotropy of a rock submitted to pure flattening will correspond to $L=1$ and $P=F=P_{m}$; on the other hand, triaxial deformation cannot achieve a maximum $P$ value equal to $P_{m}$. To obtain the upper limit of $L$ and $F$ in the triaxial case, let us assume that the rock contains $N$ platy particles, whose mean susceptibility is $\left(2 P_{m}\right.$ $+1) / 3$ and with their plane perfectly aligned along the 


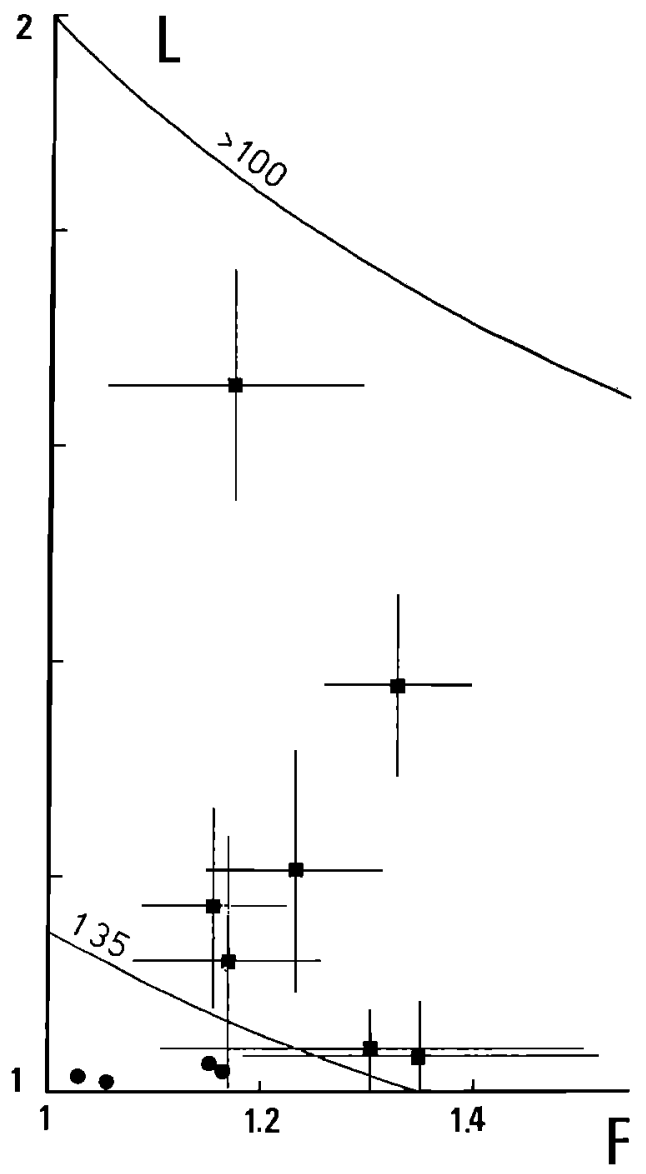

Figure 9. Site mean values of $L$ and $F$ with their standard deviation in schists from the Swiss Alps [after Rochette, 1988c]. Pyrrotitebearing sites appear with squares and sites with paramagnetic susceptibility with circles. Limit curves are drawn according to (5) for mineral anisotropy degree of biotite (1.35) and pyrrhotite $(>100)$.

stretching direction, and possible misalignment around this axis. The maximum susceptibility $K_{1}$ along the stretching direction is simply

$$
K_{1}=N P_{m}
$$

On the other hand, the mean susceptibility of the rock should be

$$
K_{m}=\left(K_{1}+K_{2}+K_{3}\right) / 3=N\left(2 P_{m}+1\right) / 3
$$

Dividing (4) by (3) we obtain

$$
1+1 / L+1 /(L F)=\left(2 P_{m}+1\right) / P_{m},
$$

which can be transformed into

$$
L=P_{m}(F+1) / F\left(P_{m}+1\right)
$$

This equation gives us the saturation values of $L$ and $F$ for a given mineral anisotropy $\boldsymbol{P}_{\boldsymbol{m}}$. For example, in a pyrrhotite-bearing rock we have $P_{m}>100$ [e.g., Hrouda, 1982], and therefore the maximum anisotropy in a purely linear fabric $(F=1)$ will be $P=L=2$; going from a planar to a linear fabric, a decrease of $P$, unrelated to a decrease in strain, will be observed in a strongly deformed rock. A study in strongly triaxially deformed schists with AMS due to phyllosilicates $\left(P_{m} \leqslant 1.35\right)$ or pyrrhotite illustrates this relationship between the maximum possible $L$ and $F$ (Figure 9 after Rochette [1988c]). Available $L$ and $F$ fields have been delimited using (5) for $P_{m}$ equal to 1.35 or larger than 100 . Site mean values of $L$ and $F$ with their standard deviations are below the curve for $P_{m}=1.2$ in purely paramagnetic sites, while they are in between the two curves for the pyrrhotite-bearing sites. Such considerations also account for the observation quite often made [e.g., Hrouda, 1982] that $P$ values tend to be smaller for prolate than for oblate fabrics.

Relating the evolution of the symmetry of magnetic fabric to the symmetry of petrofabric, or deformation, is therefore precluded when susceptibility has multiple origins or when comparing magnetic fabrics due to minerals of different symmetry.

\section{INTERACTION BETWEEN REMANENCE AND AMS}

The third assumption whose exceptions we want to discuss is the independence of AMS on remanence. It has been recognized since the beginning of anisotropy studies that the anisotropy of a rock influences its remanence by deviating the remanence vector from the applied field toward the direction or plane of maximum susceptibility [e.g., Fuller, 1963]. Using the anisotropy of remanence, it is possible to quantitatively correct this deviation in the particularly important case of NRM; it was exemplified in a granite using thermoremanent anisotropy by Cogné [1988] and in sediments using AAR by Collombat et al. [1990]. On the other hand, the influence of remanence on AMS, noticed in early studies [e.g., Bathal and Stacey, 1969], has been somewhat neglected.

The first way in which the remanence can influence AMS measurements is through instrumental bias. For example, in the case of a spinner or torque measurement the AMS measured corresponds to the $2 \theta$ component of the signal, while remanence is measured as the $\theta$ component. However, strong and inhomogeneous remanence also results in $2 \theta, 4 \theta$, etc. harmonic components that can bias the AMS signal.

Even using methods unaffected by this problem, such as an alternating bridge, it was noticed that the AMS of a sample may be changed when submitting it to a direct field [Schmidt and Fuller, 1970; Zapletal, 1985] or a static alternating field [Violat and Daly, 1971]. In the first case a hematite monocrystal was found to have a minimum susceptibility parallel to the direction of saturated isothermal remanent magnetization or IRM (as in the magnetite SD case where susceptibility is zero along the easy axis). In the second study concerning MD magnetite-bearing basalts the direction of applied field became a maximum axis. This can be interpreted by considering that the alternating field has introduced a metastable domain structure with walls parallel to the ap- 

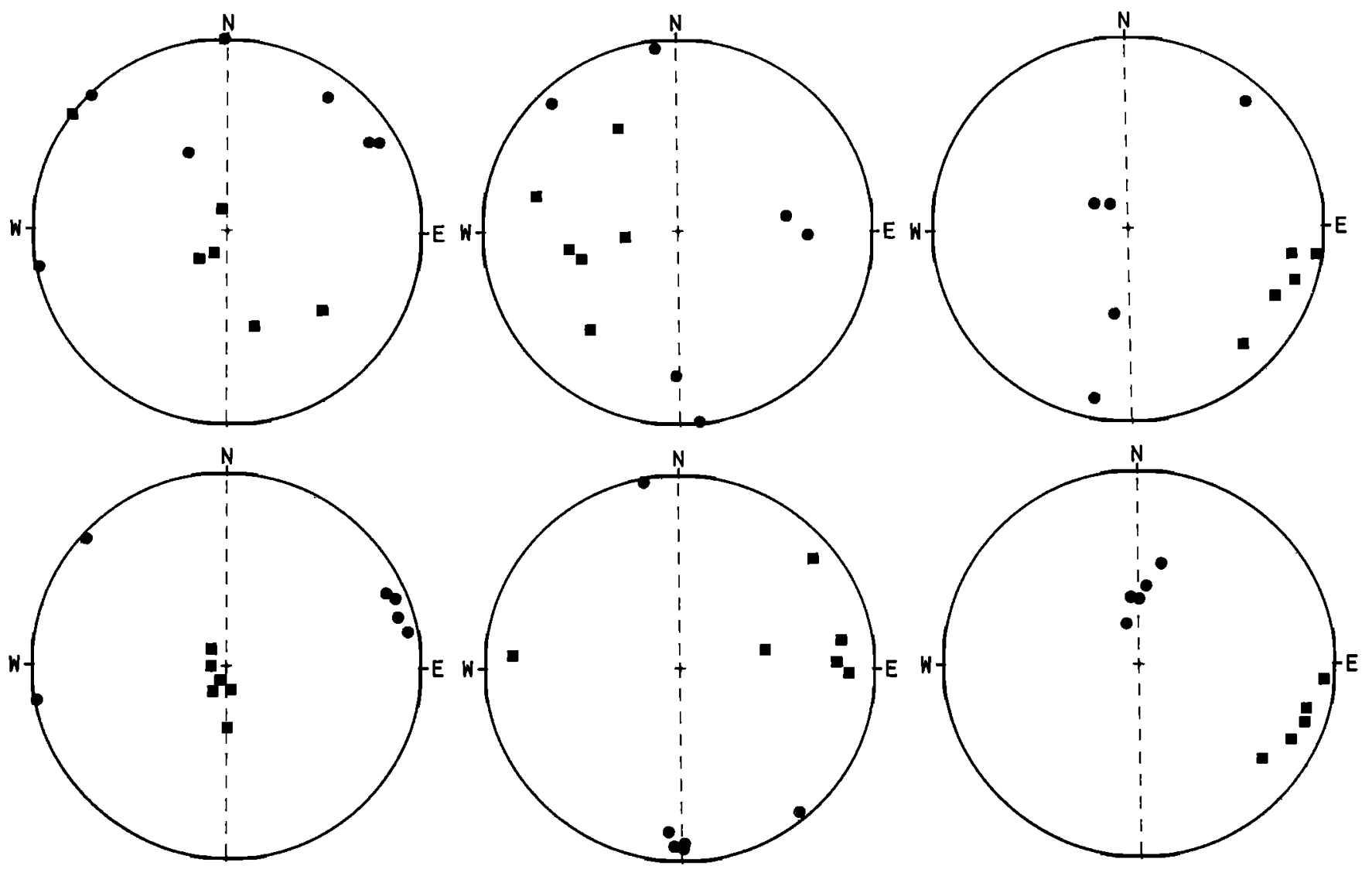

Figure 10. Examples of the change of AMS directions in dikes from Oman (a) in natural state and $(b)$ after tumbling AF demagnetization in $100 \mathrm{mT}$.

plied field. More recently, such field-impressed magnetic fabric has been thoroughly investigated [Potter and Stephenson, $1990 a, b]$; these authors have discussed quantitatively the effect of IRM, thermoremanence, static, and tumbling alternating field on AMS, depending on grain size. They also show how IRM acquisition is affected by previous alternating field history, pointing out the difficulty of measuring IRM anisotropy. One can conclude that anhysteretic or isothermal remanences strongly interact with AMS in some cases where AMS is carried by ferromagnetic grains; therefore one should not use artificially magnetized samples for magnetic fabric studies (see, for example, Kodama and Sun [1990]). Further, these studies suggest that the natural magnetic state of the rock, visible through NRM and which correspond to a particular metastable domain structure, could also have some noticeable effects on AMS.

The solution could be to demagnetize the NRM in an isotropic way, i.e., either with tumbling AF or thermal demagnetization. The effect of thermal demagnetization on AMS has provoked numerous papers because it was found that the AMS was better defined after thermal treatment [Urrutia-Fucugauchi, 1981; Perarnau and Tarling, 1985; Schultz-Krutisch and Heller, 1985; Jelenska and KadzialkoHofmokl, 1990]. However, these studies concerned sedimentary rocks where heating produces new magnetic phases, as detected by increases in mean susceptibility. Therefore the observed changes were not due to the disappearance of an NRM-dependent AMS but to the creation of a new AMS, where the fabric of the newly formed ferromagnetic grains "mimics" the fabric of the primary weaker magnetic grains. For example, Hirt and Gehring [1991] found that an inverse fabric in a siderite-bearing ore was transformed to normal fabric after thermal treatment due to creation of magnetite with a mimetic normal fabric. Therefore "thermal enhancement of magnetic fabric" [Perarnau and Tarling, 1985], although it may help in getting well-defined AMS directions from an initially hardly measurable formation, should be handled with care when interpreting the newly created fabric in terms of geologically significant phenomena.

Recently, Park et al. [1988] reported that AMS of basaltic dikes of the Canadian shield were scattered in the natural state and became well grouped with structurally significant directions after heating above the Curie point of those magnetite-bearing rocks. Other changes of AMS directions were observed during AF demagnetization. They interpreted these results by assuming that the natural AMS is constituted by a primary component linked to petrofabric and a piezomagnetic component (particular metastable domain structure due to tectonic stresses) which was erased by demagnetization. Another way to consider the results is to say that there could 
be an interaction between the natural state of the domains in the ferromagnetic grains and AMS. To check that such spurious AMS was the reason for some of the abnormal or dispersed fabrics in our study of Oman dikes [Rochette et al., 1991] tumbling alternating field and then thermal demagnetizations were performed on eight selected sites with low anisotropy ratio $(P<1.01)$. In three normal sites with well-grouped AMS directions in the natural case, demagnetizations change neither the mean direction nor the scatter. On the other hand, sites with initially dispersed AMS directions exhibit good grouping after alternating field demagnetization (examples of Figure 10) and then no change after thermal treatment. In site $\mathrm{M} 34, K_{3}$ directions become clearly normal to the dike plane and $K_{1}$ directions close to the measured subvertical mineral lineation, as expected for the flow fabric. However, the demagnetization sensitive part of AMS is not responsible for reverse or intermediate magnetic fabric but only for a scatter of directions in the initial state (e.g., site M2 and M36). Thermoremanence was imparted to samples of three sites but no effect on AMS was observed, while imparting an ARM resulted in large changes of AMS directions and ratios.

Tumbling in 100-mT peak AF appeared quite efficient for removing the scatter due to presumably NRM-dependent AMS. Therefore thermal treatment, which has the defects of being time consuming and often creating new magnetic phases, can be avoided in rocks with soft ferromagnetic grains. There is probably no need for a generalization of such demagnetization as a routine before AMS measurements. However, some tests are desirable in each case where very weak anisotropy is found.

The field-impressed anisotropy discussed above corresponds to the alignment of domain walls or spontaneous magnetization within the grains. However, another possible mechanism for an effect of NRM on AMS has been left apart: the possibility that NRM acquisition processes phys- ically align the easy axes of the grains, thus resulting in an anisotropy controlled by the direction of the acquisition field. In the case of deposition (DRM) or postdeposition (pDRM) remanence of sediments the remanence is indeed the result of such a physical alignment. Thus if magnetic torques are not negligible compared to hydrodynamic and mechanical forces acting on AMS carrying grains, one should expect a $K_{1}$ direction tending to the acquisition field direction. It has been observed in experimental DRM [Rees and Woodall, 1975; Løvlie and Torsvik, 1984a] and possibly in experimental pDRM [Ellwood, 1984b; Løvlie and Torsvik, 1984b] that while $K_{3}$ axes keep confined to the vertical, $K_{1}$ axes tend to the field direction. This effect, which may hamper the use of magnetic lineations in sedimentary rocks for paleocurrent estimation, has not been clearly evidenced in natural examples. This is probably because the AMS carrying grains are usually coarser than the NRM carrying grains, thus having experienced negligible magnetic torques compared to the other processes leading to preferred orientation.

Recent experiments on chemical remanence (CRM) acquisition coupled with subsequent measurements of the anisotropy of isothermal remanence (AIR) have been performed on synthetic fine-grained hematite [Stokking and Tauxe, 1990] and magnetite [Pick and Tauxe, 1991]. They found that maximum axes appear parallel to the field in which the grains have been grown, suggesting that anisotropy (such as AMS, AAR, or AIR) directions may be controlled by the NRM direction in rocks with a CRM. Two natural possible examples of this effect may be presented.

1. In the Onodonga Appalachian limestone, whose AAR is carried by fine-grained magnetite grown during a remagnetization event [Jackson et al., 1989b], $K_{1}$ directions appear parallel to the remagnetization field direction. Unfortunately, it is also close to the shortening direction, and the interpretation remains ambiguous.

2. Chemical sediments from the Oman ophiolite revealed
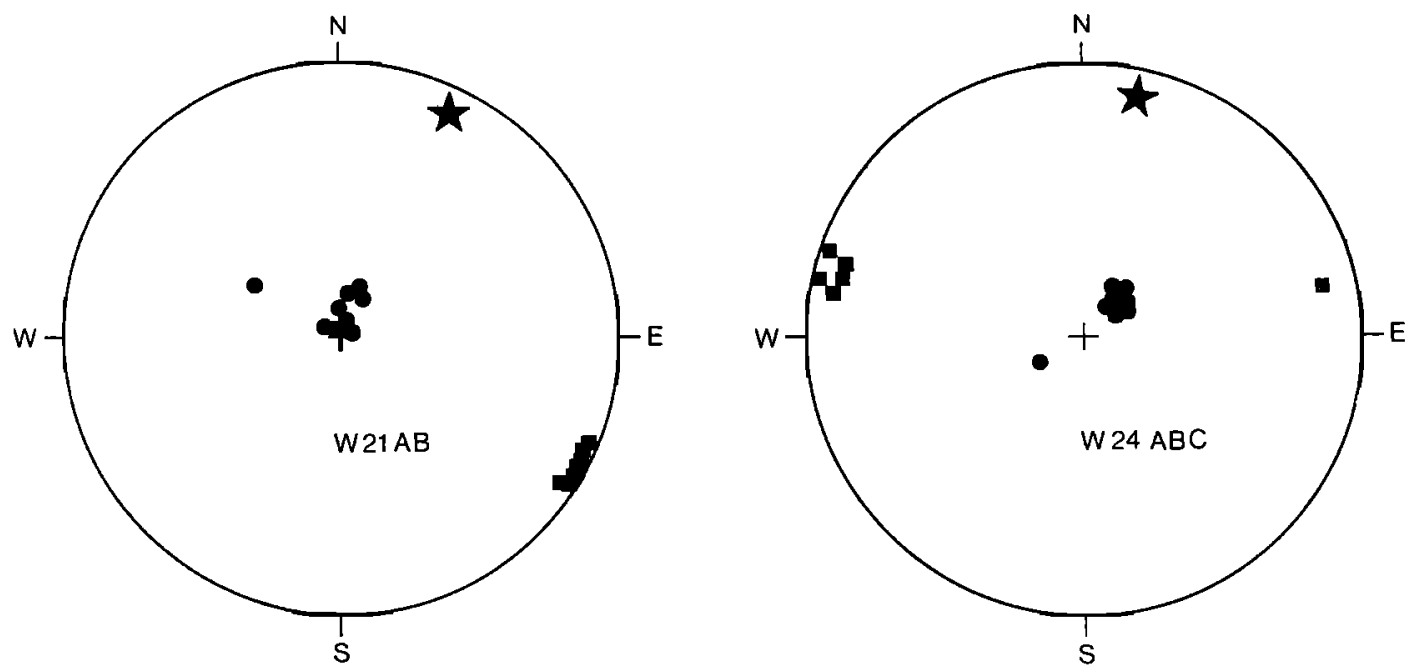

Figure 11. Stereoplots of AMS maximum and minimum directions in stratigraphic coordinates in two sites of hematite-bearing umbers from Oman after Thomas [1991] compared with the declination of characteristic remanence, shown as a star. 
primary NRM carried by very fine grained hematite with shallow inclination [Thomas et al., 1988]; subsequent AMS measurements [Thomas, 1991] on unheated samples show a clear grouping of $K_{1}$ perpendicular to the characteristic NRM direction (Figure 11). This agrees with the observation of the maximum susceptibility axis perpendicular to the remanence direction within the easy plane of hematite [Schmidt and Fuller, 1970].

\section{CONCLUSIONS}

1. Inverse magnetic fabrics can be found in samples whose susceptibility is carried by iron-bearing carbonates, tourmaline, cordierite, goethite, and SD magnetite. Various stages of intermediate magnetic fabric or interchanged principal axes can be found when a mixture of normal and inverse minerals is present. Therefore it is strongly recommended to investigate the mineralogical source of AMS and to compare AMS with other types of anisotropy (mainly AAR) when finding AMS directions that cannot be correlated with obvious structural markers. Rocks with fine-grained magnetite such as limestones are particularly prone to anomalous AMS fabric, which is difficult to interpret probably due to a wide range of grain size.

2. Many rocks owe their magnetic susceptibility to more than one mineral. In such cases it is not possible to use the AMS anisotropy ratio for structural interpretation as their variation is likely to be mainly due to compositional variations. A $P$ versus $K_{m}$ plot is the main technique to detect such a problem. The Henry's method, designed to delineate a two-component AMS, appears in some examples to produce results that have no physical significance. The only secure way to get quantitative results from a rock with multicomponent low-field susceptibility appears to be a more specific anisotropy technique such as high-field or remanence anisotropy.

3. Structurally significant AMS can be in some cases biased by remanence. One should strictly avoid measuring samples used for ARM or IRM acquisition or samples which have been submitted to static alternating field demagnetization. When AMS directions are dispersed in the natural state, this scatter may be due to interaction of AMS with NRM. In that case, tumbling alternating field demagnetization or thermal treatment may help in recovering the intrinsic magnetic fabric. This effect is probably significant only for large NRM and very low anisotropy such as those found in basaltic rocks. However, in sedimentary rocks with depositional or chemical remanence the paleomagnetic field may physically align the easy axes of the grains, mainly resulting in a magnetic lineation parallel to the geomagnetic declination and independent of current or tectonic lineations.

All these complications with respect to the usual way of interpreting AMS data will probably become more and more important to take care of as a result of the progress of the AMS technique toward higher sensitivity, quantitative use, new rock types, and domains of application. This again underlines the importance of understanding the sources of
AMS in rocks using appropriate rock magnetic techniques in order to make reliable geological interpretations.

\section{APPENDIX: TOWARD A MINERALOGICAL DATA BASE FOR AMS STUDIES}

Numerous papers and reviews on AMS have included tables with a list of characteristic parameters of minerals, including mean susceptibility $\left(K_{m}\right)$, anisotropy ratio $(P)$, symmetry, and orientation of the susceptibility ellipsoid with respect to the crystallographic axes. Another attempt to summarize these features is presented in Table 1 , with the addition of fabric type encountered in rocks bearing these minerals. Although these compilations are very useful for the interpretation of AMS in rocks, many problems arise in their completion and the values given may be used with variable confidence. A recent paper by Zapletal [1990] on biotite well exemplifies the various problems encountered in defining such characteristic parameters.

The first problem is that some features are intrinsic; i.e., they are constant for a given mineral, while others can vary with chemical composition, crystallographical defects, size, shape, and interaction of the grains. For diamagnetic minerals, all features are intrinsic. For paramagnetic minerals, only the symmetry is intrinsic and can be deduced from the crystallographic system. For example, a cubic mineral is isotropic; hexagonal, rhombohedric, and orthorhombic systems correspond to uniaxial (i.e., of revolution symmetry), ellipsoids with the revolution susceptibility axis strictly parallel to the revolution crystallographic axis; other systems lead to a triaxial ellipsoid, where susceptibility axes are not necessarily parallel to crystallographic axes.

$K_{m}$ values of paramagnetic minerals can be estimated from chemical analysis using a simple formula as a function of $\mathrm{Fe}^{2+}, \mathrm{Fe}^{3+}, \mathrm{Mn}^{2+}$ amounts and mineral density [Rochette, 1987]. This parameter will therefore show a range of values for natural minerals which show a range of composition. $P$ values can also vary with composition, although in the example of biotite it appears quite constant. In ferromagnetic minerals such as pyrrhotite and hematite, only a part of the symmetry is intrinsic; $K_{3}$ is parallel to the $c$ axis, while the anisotropy within the basal plane is also controlled by various factors including shape, defects, and domain state.

The second problem is experimental. In principle, the only proper reference data for minerals should come from wellcharacterized, untwinned, and undeformed single crystals where good evidence is found for a lack of impurities, for example, ferromagnetic inpurities often found in paramagnetic minerals. Such evidence, mainly from high-field measurements, is here only available for quartz, phyllosilicates, orthoferrosilite, carbonates, and tourmaline. It may be possible that the contradictory data base for chain silicates (see section 2.3 and Table 1) may be linked to ferromagnetic impurities.

Unfortunately, due to lack of large crystals, poor instrumental precision, or fine grain size, one is forced to use data 
from oriented aggregates or to have poorly defined singlecrystal values. The results must then be constrained using theoretical considerations. For example, pseudohexagonal phyllosilicates such as biotite, chlorite, and muscovite should have a uniaxial symmetry, as found in carefully selected crystals by Zapletal [1990]. Therefore the triaxial results (i.e., $L \neq 1$ ) obtained by Borradaile et al. [1987] are probably due to impurities or imperfect orientation in their aggregates. Another problem arises when one wants to extrapolate to fine grain size the reference values for hematite or pyrrhotite which are derived from large multidomain single crystals. The very large $P$ value usually quoted for hematite can be indirectly questioned considering the following facts. Hematite shows an intrinsic isotropic susceptibility of antiferromagnetic origin equal to $1.1 \times 10^{-3} \mathrm{SI}$ and a variable ferromagnetic susceptibility confined to the basal plane [Néel and Pauthenet, 1952]. In fine disoriented grains the second one is the order of $10^{-3}$ SI [Dunlop, 1971], which corresponds to a $P$ value of the order of 2.5. This lowering of $P$ value in fine grains is probably less critical in pyrrhotite.

ACKNOWLEDGMENTS. For this review we are deeply indebted to numerous colleagues who have provided comments, ideas, samples (in particular the monocrystals) and data, in such a number that we must thank them collectively. Careful reviews by D. K. Potter and W. Lowrie have been very useful. The stay in Grenoble of $M$. Jackson was granted by CNRS. DBT contribution 480 (Theme 5).

J. A. Jacobs was the editor responsible for this paper. He thanks D. K. Potter and C. Richter for serving as technical referees.

\section{REFERENCES}

Amice, M., Le complexe granitique de Cabeza de Araya (Estremadure, Espagne), thesis, 225 pp., Univ. of Toulouse, Toulouse, France, 1990.

Amice, M. and J. L. Bouchez, Susceptibilité magnétique et zonation du batholite de Cabeza de Araya (Estremadure, Espagne), C. R. Acad. Sci., Paris, 308, 1171-1178, 1989.

Aubourg, C., Méthodes d'étude de la fabrique magnétique appliquées aux roches sédimentaires peu déformées, thesis, $187 \mathrm{pp}$., Univ. of Grenoble, Grenoble, France, 1990.

Aubourg, C., P. Rochette, and P. Vialon, Cryptic stretching lineations revealed by magnetic fabric of Callovo-Oxfordian black shales (French Alps), Tectonophysics, 185, 211-223, 1991.

Ballet, O., $\mathrm{Fe}^{2+}$ dans les silicates lamellaires: Étude magnétique et Mössbauer, thesis, 120 pp., Univ. of Grenoble, Grenoble, France, 1979.

Bathal, R. S., and F. D. Stacey, Field-induced anisotropy of susceptibility in rocks, Pure App. Geophys., 76,123-129, 1969.

Borradaile, G. J., Anisotropy of magnetic susceptibility: Rock composition versus strain, Tectonophysics, 138, 327-329, 1987.

Borradaile, G. J., Magnetic susceptibility, petrofabric and strainA review, Tectonophysics, 156, 1-20, 1988.

Borradaile, G. J., Correlation of strain with anisotropy of magnetic susceptibility, Pure Appl. Geophys., 135, 15-30, 1991.

Borradaile, G. J., and M. A. Puumala, Synthetic magnetic fabric in plasticene, Tectonophysics, 164, 73-78, 1989.

Borradaile, G. J., and P. Sarvas, Magnetic susceptibility fabrics in slates: Structural mineralogical and lithological influences, Tectonophysics, 172, 215-222, 1990.

Borradaile, G. J., J. Mothersill, D. Tarling, and C. Alford, Source of magnetic susceptibility in a slate, Earth Planet. Sci. Lett., 76, 336-340, 1985.

Borradaile, G.J., W. Keeler, C. Alford, and P. Sarvas, Anisotropy of magnetic susceptibility of some metamorphic minerals, Phys. Earth Planet. Inter., 172, 215-222, 1987.

Coey, J. M. D., Magnetic properties of iron in soil iron oxydes and clay minerals, in Iron in Soils and Clay Minerals, edited by J. W. Stucki, B. A. Goodman and U. Schwertmann, 893 pp., D. Reidel, Hingham, Mass., 1988.

Cogné, J. P., TRM deviation in anisotropic assemblage of MD magnetite, Geophys. J. R. Astron. Soc., 91, 1013-1023, 1987.

Cogné, J. P., Strain-induced AMS in the granite of Flamanville and its effect upon TRM acquisition, Geophys. J. R. Astron. Soc., 92, 445-453, 1988.

Collombat, H., P. Rochette, and M. Jackson, Possible correction of the inclination error in deep sea sediments using the anisotropy of anhysteretic remanence (abstract), Eos Trans. AGU, 71, 1288, 1990.

Constable, C., and L. Tauxe, The bootstrap for magnetic susceptibility tensors, J. Geophys. Res., 95, 8383-8395, 1990.

Coward, M. P., and J. S. Whalley, Texture and fabric studies across the Kishom Nappe, Western Scotland, J. Struct. Geol., 6, 3338, 1979.

Daly, L., Etude des propriétés magnétiques des roches métamorphiques ou simplement tectonisées, thesis, $340 \mathrm{pp}$., Univ. of Paris, Paris, 1970.

Damm, V., Gesteinsmagnetische Anisotropien in Magmatiten und deren strukturgeologische Bedeutung, Z. Geol. Wiss., 16, 739$752,1988$.

Day, R., M. Fuller, and V. A. Schmidt, Hysteresis properties of titanomagnetites: Grain-size and compositional dependence, Phys. Earth Planet. Inter., 13, 260-266, 1977.

Dekkers, M. J., Some rockmagnetic parameters for natural goethite, pyrrhotite and fine-grained hematite, thesis, 231 pp., Univ. of Utrecht, Utrecht, Netherlands, 1988.

Dunlop, D. J., Magnetic properties of fine particle hematite, Ann. Geophys., 27, 269-293, 1971.

Ellwood, B. B., Flow and emplacement directions determined for selected magmatic bodies using anisotropy of magnetic susceptibility measurements, Earth Planet. Sci. Lett., 41, 254-264, 1978.

Ellwood, B. B., Anisotropy of magnetic susceptibility: Empirical evaluation of instrumental precision, Geophys. Res. Lett., 11, 645-648, 1984a.

Ellwood B. B., Bioturbation: Minimal effect on the magnetic fabric of some natural and experimental sediments, Earth Planet. Sci. Lett., 67, 367-376, $1984 b$.

Ellwood, B. B. , F. Hrouda, and J. J. Wagner, Symposia on magnetic fabric: Introductory comments, Phys. Earth Planet Inter., 51, 249-252, 1988.

Foex, G., Constante selectionnées: Diamagnetisme et paramagnétisme; in Tables de Constantes et Données Numériques, vol. 7, pp. 91-103, Masson, Paris, 1957.

Fuller, M., Magnetic anisotropy and paleomagnetism, J. Geophys. Res., 68, 293-309, 1963.

Goldstein, A., and L. Brown, Magnetic susceptibility anisotropy of mylonites from the Brevard zone, North Carolina, USA, Phys. Earth Planet. Inter., 51, 290-300, 1988.

Hargraves, R. B., D. Johnson, and C. Y. Chan, Distribution anisotropy: The cause of AMS in igneous rocks?, Geophys. Res. Lett. 18, 2193-2196, 1991.

Hedley, I. G., The weak ferromagnetism of goethite $(\alpha \mathrm{FeOOH})$, Z. Geophys., 37, 409-420, 1971.

Henry, B., Interprétation quantitative de l'anisotropie de susceptibilite magnétique, Tectonophysics, 91, 165-177, 1983.

Hirt, A., and A. Gehring, Thermal alteration of the magnetic mineralogy in ferruginous rocks, J. Geophys. Res., 96, 9947-9954, 1991.

Hrouda, F., Magnetic anisotropy of rocks and its application in 
geology and geophysics, Geophys. Surv., 5, 37-82, 1982.

Hrouda F., The effect of quartz on the magnetic anisotropy of quartzite, Stud. Geophys. Geod., 30, 39-43, 1986.

Hrouda, F, Mathematical model relationship between the paramagnetic anisotropy and strain in slates, Tectonophysics, 142, 323-327, 1987.

Hrouda, F, and V. Jelinek, Resolution of ferrimagnetic and paramagnetic anisotropies in rocks using combined low-field and high-field measurements, Geophys. J. Int., 103, 75-84, 1990.

Ihmlé, P. F. , A. Hirt, W. Lowrie, and D. Dietrich, Inverse magnetic fabric in deformed limestones of the Morcles nappe, Switzerland, Geophys. Res. Lett., 16, 1383-1386, 1989.

Jackson, M., Anisotropy of magnetic remanence: A brief review of mineralogical sources, physical origins and geological applications, Pure Appl. Geophys., 136, 1-28, 1991.

Jackson, M., and L. Tauxe, Anisotropy of magnetic susceptibility and remanence: developments in the characterization of tectonic, sedimentary and igneous fabric, Rev. Geophys., 29, supplement, 371-376, 1991.

Jackson, M., D. Sprowl, and B. B. Ellwood, Anisotropies of partial anhysteretic remanence and susceptibility in compacted shales: Grain-size and composition dependent magnetic fabric, Geophys. Res. Lett., 16, 1063-1066, 1989a.

Jackson, M., J. P. Craddock, M. Ballard, R. Van der Voo, and C. McCabe, Anhysteretic remanent magnetic anisotropy and calcite strain in Devonian carbonates from the Applachian Plateau, New York, Tectonophysics, 161, 43-53, $1989 b$.

Jelenska, M., and M. Kadzialko-Hofmokl, Dependence of anisotropy of magnetic susceptibility of rocks on temperature, Phys. Earth Planet. Inter., 62, 19-31, 1990.

Jelinek, V., Statistical processing of anisotropy of magnetic susceptibility measured on groups of specimens, Stud. Geophys. Geod, 22, 50-62, 1978.

Johns, M. K., The magnetic and tectonic fabric of the Thomson formation, M. S. thesis, Univ. of Minn., Minneapolis, 1990.

Jover, O., P. Rochette, J. P. Lorand, M. Maeder, and J. L. Bouchez, Magnetic mineralogy of some granites from the French Massif Central: Origin of their low field susceptibility, Phys. Earth Planet. Inter., 55, 79-92, 1989.

Khan, M. A., Anisotropy of magnetic susceptibility of some igneous and metamorphic rocks, J. Geophys. Res., 67, 28732885, 1962.

Knight, M. D., and G. P. Walker, Magma flow directions in dikes of the Koolau complex, Oahu, determined from magnetic fabric studies, J. Geophys. Res., 93,4301-4319, 1988.

Kodama, K. P., and W. W. Sun, SEM and magnetic fabric study of a compacting sediment, Geophys. Res. Lett., 17, 795-798, 1990.

Lienert, B. R., Monte Carlo simulation of errors in the anisotropy of magnetic susceptibility: A second-rank symmetric tensor, $J$. Geophys. Res., 96, 19,539-19,544, 1991.

Løvlie, R., and T. Torsvik, Magnetic remanence and fabric properties of laboratory-deposited hematite-bearing red sandstone, Geophys. Res. Lett. 11, 229-232, 1984a.

Løvlie, R., and T. Torsvik, Comment on Bioturbation: Minimal effect on the magnetic fabric of some natural and experimental sediments, Earth Planet. Sci. Lett., 71, 349-350, $1984 b$.

Lowrie, W., Magnetic analysis of rock fabric, in The Encyclopedia of Solid Earth Geophysics, edited by D. E. James, pp. 698706, D. Van Nostrand Reinhold, Princeton, N.J., 1989.

Lowrie, W., and F. Heller, Magnetic properties of marine limestones, Rev. Geophys. Space Phys., 20, 171-192, 1982.

Maher, B. A., Magnetic properties of some synthetic sub-micron magnetites, Geophys. J., 94, 83-96, 1988.

McCabe, C., M. Jackson, and B. B. Ellwood, Magnetic anisotropy of the Trenton limestone results of a new technique, anisotropy of anhysteretic susceptibility, Geophys. Res. Lett., 12, 333-336, 1985.

Néel, L., and R. Pauthenet, Etude thermomagnétique d'un mono- cristal de $\mathrm{Fe}^{2} \mathrm{O}^{3} \alpha$, C. R. Acad. Sci. Paris, 234, 2172-2174, 1952.

O'Reilly, W., Rock and Mineral Magnetism, Blackie, Glasgow, 1984.

Owens, W. H., Mathematical model studies on factor affecting the magnetic anisotropy of deformed rocks, Tectonophysics, 24, 115-131, 1974.

Owens, W. H. and D. Bamford, Magnetic, seismic and other anisotropic properties of rock fabrics, Philos. Trans. R. Soc. London, Ser. A, 283, 55-68, 1976.

Owens, W. H., and E. H. Rutter, The development of magnetic susceptibility anisotropy through crystallographic preferred orientation in a calcite rock, Phys. Earth Planet. Inter., 16, 215$222,1978$.

Park, J. K., E. Tanczyk, and A. Desbarats, Magnetic fabric and its significance in the 1400 Ma Mealy diabase dikes of Labrador, Canada, J. Geophys. Res., 93, 13,689-13,704, 1988.

Parma, J., An automated torque meter for rapid measurement of high field magnetic anisotropy of rocks, Phys. Earth Planet. Inter., 51, 387-389, 1988.

Perarnau, A., and D. H. Tarling, Thermal enhancement of magnetic fabric in Cretaceous sandstones, J. Geol. Soc. London, 142, 1029-1034, 1985.

Pick, T., and L. Tauxe, CRM acquisition in synthetic magnetite, J. Geophys. Res., 96, 9925-9936, 1991.

Potter, D. K., and A. Stephenson, Single-domain particles in rocks and magnetic fabric analysis, Geophys. Res. Lett., 15, 1097$1100,1988$.

Potter, D. K., and A. Stephenson, Field-impressed anisotropies of magnetic susceptibility and remanence in minerals, J. Geophys. Res., 95, 15,573-15,588, 1990a.

Potter, D. K., and A. Stephenson, Field-impressed magnetic anisotropy in rocks, Geophys. Res. Lett., 17, 2437-2440, 1990 b.

Rees, A. I., and W. A. Woodall, The magnetic fabric of some laboratory deposited sediments, Earth Planet. Sci. Lett., 25 , 121-130, 1975.

Rochette, P., Magnetic susceptibility of the rock matrix related to magnetic fabric studies, J. Struct. Geol., 9, 1015-1020, 1987.

Rochette, P., Inverse magnetic fabric carbonate bearing rocks, Earth Planet. Sci. Lett., 90, 229-237, 1988a.

Rochette, P., La susceptibilité anisotrope des roches faiblement magnétiques: Origines et applications, thesis, 195 pp., Univ. of Grenoble, Grenoble, France, $1988 b$.

Rochette, P., Relations entre déformations et métamorphisme alpins dans les schistes noirs helvétiques: L'Apport de la fabrique magnétique, Geodyn. Acta, 2, 17-24, 1988c.

Rochette, P., and G. Fillion, Identification of multicomponent anisotropy in rocks using various field and temperature values in a cryogenic magnetometer, Phys. Earth Planet. Inter., 51, 379 386, 1988.

Rochette, P., and G. Fillion, Field and temperature behavior of remanence in synthetic goethite: Paleomagnetic implications, Geophys. Res. Lett., 16, 851-854, 1989.

Rochette, P., G. Fillion, P. Mollard, and R. Vergne, Utilisation d'un magnétomètre à effet Josephson pour l'analyse de l'anisotropie magnétique des roches, C. R. Acad. Sci. Paris, 296, 557-558, 1983.

Rochette, P., L. Jenatton, C. Dupuy, F. Boudier, and I. Reuber, Emplacement mode of basaltic dikes in the Oman ophiolite: Evidences from magnetic anisotropy with reference to geochemical studies, in Ophiolite Genesis and the evolution of the Oceanic Lithosphere, edited by T. J. Peters et al., 55-82, Kluwer, Dordrecht, Netherlands, 1991.

Scaillet, B., Structure et géochimie en régime de collision continentale: L'Exemple du massif de Gangotri-Badrinath, thesis, 142 pp., Univ. of Nancy, Nancy, France, 1990.

Schultz-Krutisch, T., and F. Heller, Measurement of magnetic susceptibility anisotropy in Bundsandstein deposits from southern Germany, J. Geophys., 56, 51-58, 1985.

Schmidt, V. A., and M. Fuller, Low field susceptibility anisotropy 
in the basal plane of hematite and its dependence on the remanent moment, J. Appl. Phys., 41, 994-995, 1970.

Schmidt, V., B. B. Ellwood, T. Nagata, and H. C. Noltimier, The measurement of magnetic susceptibility anisotropy using a cryogenic magnetometer and comparison with results obtained from torsion-fiber magnetometer, Phys. Earth Planet. Inter., 51, 365$378,1988$.

Stephenson, A., S. Sadikum, and D. K. Potter, A theoretical and experimental comparison of the anisotropies of magnetic susceptibility and remanence in rocks and minerals, Geophys. $J$. R. Astron. Soc., 84, 185-200, 1986.

Stokking, L. and L. Tauxe, Properties of chemical remanence in synthetic hematite: Testing theoretical predictions, J. Geophys. Res., 95, 12,639-12,652, 1990.

Tauxe, L., C. Constable, and L. Stokking, Use of anisotropy to determine the origin of characteristic remanence in the Siwalik red beds of Pakistan, J. Geophys. Res., 95, 4391-4404, 1990.

Thomas, V., Paleomagnétisme des ophiolites d'Oman, thesis, 220 pp., Univ. of Montpellier, Montpellier, France, 1991.

Thomas, V., J. P. Pozzi and A. Nicolas, Paleomagnetic results from Oman ophiolites related to their emplacement, Tectonophysics, 151, 297-322, 1988.
Urrutia-Fucugauchi, J., Preliminary results on the effect of heating on the magnetic susceptibility anisotropy of rocks, J. Geomag., Geoelectr., 33, 411-419, 1981.

Violat, C., and L. Daly, Anisotropie provoquée sur des roches volcaniques par action d'un champ alternatif, $C$. $R$. Acad. Sci. Paris, 273, 158-161, 1971.

Weidenmann, A., J. R. Regnard, G. Fillion, and S. Hafner, Magnetic properties and magnetic ordering of the orthopyroxenes, J. Phys. C Solid State Phys., 19, 3683-3695, 1986.

Zapletal, K., Magnetic anisotropy of polycrystalline hematite induced by a DC magnetic field, Stud. Geophys. Geod., 29, 351361, 1985.

Zapletal, K., Low-field susceptibility anisotropy of some biotite crystals, Phys. Earth Planet. Inter., 63, 85-97, 1990.

C. Aubourg, LGIT, Observatoire de Grenoble, IRIGMBP 53X 38041 Grenoble Cedex,, France.

M. Jackson, Institute for Rock Magnetism, University of Minnesota, Minneapolis, MN 55455.

P. Rochette, Faculté St-Jérôme, case 431, 13397 Marseille Cedex 13 France. 